\title{
Biotechnological advances in bioremediation of heavy metals contaminated ecosystems: an overview with special reference to phytoremediation
}

\author{
D. Mani · Chitranjan Kumar
}

Received: 30 April 2012/Revised: 15 February 2013/Accepted: 23 April 2013/Published online: 16 May 2013

(C) Islamic Azad University (IAU) 2013

\begin{abstract}
The ability of heavy metals bioaccumulation to cause toxicity in biological systems-human, animals, microorganisms and plants-is an important issue for environmental health and safety. Recent biotechnological approaches for bioremediation include biomineralization (mineral synthesis by living organisms or biomaterials), biosorption (dead microbial and renewable agricultural biomass), phytostabilization (immobilization in plant roots), hyperaccumulation (exceptional metal concentration in plant shoots), dendroremediation (growing trees in polluted soils), biostimulation (stimulating living microbial population), rhizoremediation (plant and microbe), mycoremediation (stimulating living fungi/mycelial ultrafiltration), cyanoremediation (stimulating algal mass for remediation) and genoremediation (stimulating gene for remediation process). The adequate restoration of the environment requires cooperation, integration and assimilation of such biotechnological advances along with traditional and ethical wisdom to unravel the mystery of nature in the emerging field of bioremediation. This review highlights better understanding of the problems associated with the toxicity of heavy metals to the contaminated ecosystems and their viable, sustainable and eco-friendly bioremediation technologies, especially the mechanisms of phytoremediation of heavy metals along with some case studies in India and abroad. However, the challenges
\end{abstract}

D. Mani · C. Kumar

Department of Chemistry, Sheila Dhar Institute of Soil Science, University of Allahabad, Allahabad 211002, UP, India

\section{Kumar $(\bowtie)$}

The National Academy of Sciences, India, Sheila Dhar Inst Soil Sci, University of Allahabad, 5 Lajpatrai Road, Allahabad 211002, UP, India

e-mail: chitranjan.alld@gmail.com (biosafety assessment and genetic pollution) involved in adopting the new initiatives for cleaning-up the heavy metals-contaminated ecosystems from both ecological and greener point of view must not be ignored.

Keywords Biomineralization - Bioremediation · Biostimulation - Cyanoremediation - Detoxification . Genoremediation - Mycoremediation - Phytoremediation · Rhizoremediation

\section{Introduction}

Biotechnological advancement is the process of bioscientific interest resulting in a fundamental reconfiguration of science and its role in society (Kastenhofer 2007). Biotechnology uses the chemistry of living organisms as tools through cell manipulation to develop alternative and innovative methods aimed at pure and more effective ways for producing traditional products and at the same time maintain natural environment. During twentieth to twenty-first centuries, the researchers have seen a series of technological advances that have facilitated significant benefits to human beings in terms of health, food production, transport, housing and tourism. The anthropogenic activities demand the development of new chemicals, materials and enormous quantities of energy, exploit natural resources and create large amounts of waste, which have resulted and continue to result in environmental pollution. Due to discharge of heavy metals from metallurgical ovens (Lee et al. 2006; Govarthanan et al. 2013), radionuclides (Mclean and Abbe 2008), sewage sludge/wastewater (from industrial, municipal and domestic origin) (Deng et al. 2007; Kumar and Mani 2010; Mapanda et al. 2005; Robinson et al. 2011) and un-hygienic approach of rapidly 
growing population, the environment has suffered manifold detrimental effects. The present situation demands urgent action to restore the proper functioning of biogeochemical cycles, which is the driving force behind life on our planet. Biogeochemical cycles are driven by the metabolic activity of microbial communities able to prevent pollutants from reaching the biosphere ( $\mathrm{Li}$ et al. 2013). Yet, the functional potential coded within microbial genome is poorly understood (Jeffries et al. 2012).

Contaminated ecosystems are causing impacts on plants, microorganisms, aquatic organisms and life support functions such as immobilization, mineralization and nitrification that is ultimately affecting human health as well as the health of the ecosystem (Batayneh 2012). Scientists are reaching on a consensus to decrease the release of pollutants and to ameliorate their effects mediated by living organisms such as plants, an approach known as phytoremediation (Conesa et al. 2012; Pilon-Smits 2005), or by microbes which is amalgamated under the generic term bioremediation. It has been observed as an ideal solution for pollution control and the most effective innovative technology that uses biological systems for treatments of contaminants (Cardenas et al. 2008; Dua et al. 2002). Bioremediation is an ecologically sound and state-of-the-art technique that employs natural biological processes to completely eliminate toxic contaminants. It may be any process that uses microorganisms, fungi, green plants or their enzymes to return the natural environment altered by contaminants to its original condition (Chakraborty et al. 2012; Kensa 2011).

The late 1980s and early 1990s represented the golden era for bioremediation. The physical action of the plant roots, the addition of organic matter, the dissolution of $\mathrm{CaCO}_{3}$ and crop uptake of salts in reclamation of saline-sodic soils were primarily reported (Helalia et al. 1990). Later, researches (discussed under different sub-headings) on the isolation and identification of microbes, such as Candidatus accumulibacter, capable of storing polyphosphates in wastewater treatment plants, as earlier thought to be recalcitrant, able to degrade pollutants in the activated system were conducted (Seviour et al. 2003). Chronologically, the depiction of catabolic pathways for pollutants degradation, the application of molecular techniques to understand microbial ecology, and the genomic construction of recombinant microbes tailored to degrade pollutants were investigated (Siezen and Galardini 2008; Ramos et al. 2011).

Recently, integrative approach or systems biology approach to bioremediation (Brunk et al. 2011; Chakraborty et al. 2012; Checa et al. 2012; Singh et al. 2011; Tully et al. 2012), providing insights into positive and negative side effects, covering several environmental aspects, is being implemented for adequate protection and restoration of the contaminated ecosystems. However, further characterization and critical biosafety assessment of different contaminated ecosystems such as sewage sludge, nuclear waste, land mines, surface wastewater/sub-surface groundwater and agricultural soils must be taken into account (Achal et al. 2011; Choudhary and Sar 2011; Nouri et al. 2008; Rajaganapathy et al. 2011; Robinson et al. 2011; Wang et al. 2012). At the same time, genetic pollution of the aforesaid ecosystem through transgenic bacteria must not be ignored (Singh et al. 2011).

This review provides state-of-the-art description of advances in bioremediation along with special reference to phytoremediation of heavy metals; addresses, at a fundamental level, broad scientific and technological areas that are unique to the theme of environmental restoration on a sustainable basis. The content blends the know-how of academic, agricultural, industrial, governmental and international contributors; and provides a critical view on the knowledge gaps and limitations in field application strategies and approaches such as biomineralization, biosorption, mycoremediation, cyanoremediation, biostimulation, phytoextraction/phytostabilization, dendroremediation, detoxification, hyperaccumulation, rhizoremediation, genoremediation, and phytomanagement.

Heavy metals toxicity on biological systems

All metals, in spite of whether they are essential or non-essential, can exhibit toxic effects at elevated concentrations. Toxicity of metals to an organism can be defined as the intrinsic potential or ability of a metal to cause negative effects on living organisms and depends on the bioavailability of the metals (Rasmussen et al. 2000). The threat of heavy metals to human and animal health is aggravated by their long-term persistence in the environment. For instance, $\mathrm{Pb}$, one of the most persistent metals, has a soil retention time of 150-5,000 years. Average biological half-life of $\mathrm{Pb}$ has been estimated to be 18 , and 10 years once in the human body (Gisbert et al. 2003). Some non-essential elements (e.g., As, F, Cd, Hg and $\mathrm{Pb}$ ) are extremely toxic to biota even at very low concentrations (MoEF 2011; Wang et al. 1997). Once a pollutant gains entry into a living organism and reaches its target site, it may exhibit an injurious action. The effect of the pollutant is therefore a function of its concentration at the locus of its action. Metal toxicity becomes more severe in acidic medium, nutrient-deficient ecosystem and poor physical conditions (Mukhopadhyay and Maiti 2010). Recently, Jiang et al. (2012a) evaluated $\mathrm{Cr}$, $\mathrm{Ni}$ and $\mathrm{Pb}$ toxicity confined to Zhushan Bay, Meiliang Bay, in a eutrophic lake Taihu in China.

Mukherjee et al. (2008) reported industrial emissions of mercury from coal combustion, iron and steel industry, non-ferrous metallurgical plants and chlor-alkali plants in India. Elemental mercury can be a problem because it is 
oxidized to $\mathrm{Hg}^{2+}$ by biological systems and subsequently leached into wetlands, waterways and estuaries. Additionally, mercury can accumulate in animals as methyl mercury, dimethyl mercury or other organomercury salts.

High level of arsenic in water poses a great risk to animals, plants and human health (Wang et al. 2012; Yin et al. 2012). The flooded paddy fields create a reducing environment or oxidative stress and accumulate high levels of As III (Meharg et al. 2009). Arsenic-contaminated groundwater is being used for drinking water, domestic water supplies and irrigation of many crops, particularly rice (Oryza sativa L), in the Indian sub-continent (Ravenscroft et al. 2009). In a study, conducted at Chinese Academy of Sciences, Xinjiang, China, $10 \mathrm{mg}$ $\mathrm{L}^{-1}$ As III significantly inhibited synthesis of chlorophyll a, oxygen evolution in photosystem II and synthesis of carotenoids of Microcystis aeruginosa after $48 \mathrm{~h}$ of treatment (Wang et al. 2012). World Health Organization (WHO) has observed arsenic contamination from over 70 countries affecting the health of an estimated 150 million people across the globe. This situation is alarming in Bangladesh and the eastern states of India, and WHO has called this situation as the 'worst mass poisoning' event in human history (Hassan 2005). Wang et al. (1997) reported arsenic concentrations up to $880 \mu \mathrm{g} / \mathrm{l}$ from tubewells from the Kuitan area of Xinjiang, a city situated in the western part of China. Many residents suffered from arsenism, a disease caused by arsenic (As) poisoning, after consuming well water containing $0.12 \mathrm{mg} \mathrm{As} / \mathrm{l}$ for 10 years with a prevalence rate of $1.4 \%$ of the city population. However, in residents who had consumed water containing $0.6 \mathrm{mg}$ As/l for only 6 months, the prevalence rate increased to $47 \%$, and the patients showed more severe symptoms.

Heavy metals can accumulate in plant tissue to a level that affects its growth and development, as these metals interfere with metabolic functions in plants, including physiological and biochemical processes, inhibition of photosynthesis and respiration, degeneration of main cell organelles, which includes stunted growth, chlorosis, reduced crop yield, delayed germination, senescence, premature leaf fall, biochemical lesions, loss of enzyme activities, even leading to death of plants (Liu et al. 2008; Mohanty et al. 2012).

\section{Remediation of heavy metals}

It is highly desirable to apply suitable remedial approaches to polluted soils, which can reduce the risk of metal contamination. The remediation can be attempted through conventional remedial measures such as land filling and leaching, excavation and burial or soil washing (Wuana et al. 2010; Vesely et al. 2012). An extensive use of solidwaste landfills for disposal of municipal and industrial wastes as well as inappropriate use of agro-chemicals has generated a huge amount of leachate causing groundwater pollution (Nouri et al. 2008), and the potential for groundwater contamination by leachate has necessitated for the invention of novel engineering designs for landfills (Sivakumar 2012).

Remediation of heavy metals-polluted ecosystems could be carried out using physicochemical processes such as ion exchange, precipitation, reverse osmosis, evaporation and chemical reduction (Tang et al. 2007). However, due to problems such as membrane fouling, high costs, high energy requirement and low removal efficiency, these processes show scant relevance in industries. In general, technical applicability, cost-effectiveness and plant simplicity are the key factors in selecting the most suitable treatment method to remove heavy metals (such as copper, arsenic, lead and zinc) and cyanide from contaminated ecosystem (Acheampong et al. 2010). However, the latest technologies like photocatalytic reduction, surfactant-based membranes, liquid membranes and surface complexation are more efficient for heavy metals removal from contaminated ecosystems (Malaviya and Singh 2011; Xu et al. 2012).

Chen and Lin (2010) investigated a bioleaching process for removal of heavy metals from a metal-contaminated soil. They obtained maximum metal solubilization at $1 \%$ (w/v) soil solid content and $0.1 \%(\mathrm{w} / \mathrm{v})$ sulfur dosage, and the efficiency was higher than $80 \%$. They also observed that treated soil was stable and residual heavy metals were no longer harmful to the environment after the bioleaching process. A sulfur-oxidizing bacteria Acidithiobacillus thiooxidans, isolated from sewage sludge waste treatment plant, Jinshan, Fuzhou, China, was found able to optimize the bioleaching process at solid concentration $2 \%$, sulfur concentration $5 \mathrm{~g} / \mathrm{L}$ and cell concentration $10 \%$. The removal efficiency of $\mathrm{Cr}, \mathrm{Cu}, \mathrm{Pb}$ and $\mathrm{Zn}$ was 43.65, $96.24,41.61$ and $96.50 \%$ in the period of 4-10 days under the optimum conditions, respectively (Wen et al. 2010). However, the principal disadvantage of this process is its slow kinetics in metal solubilization, which may limit practical application of the bioleaching process. Although the metal solubilization process has been enhanced, using catalysts like ferric ions (Chen et al. 2003), the process still remains less economical or less profitable having higher risks of groundwater contamination (Batayneh 2012; Hazen 2010; Nouri et al. 2008).

The biological methods, especially phytobioremediation, have been considered as efficient, environmental friendly and cost-effective alternatives to physicochemical treatment technologies for remediation of contaminated ecosystems. Researches have indicated that plants have the genetic potential to remove many toxic metals from the contaminated soil-water ecosystem (Lyyra et al. 2007; Memon and Schroder 2009; Pilon-Smits 2005; Pilon-Smits 
and LeDuc 2009; Mani et al. 2012a). However, the decontamination of polluted land through the application of immobilized microbial enzymes and using resistant microorganisms such as bacteria, fungi, algae and vesicular arbuscular mycorrhizae (Purakayastha and Chhonker 2001) is ecologically and economically sound. To resolve the paradox of combining plant hyperaccumulators and arbuscular mycorrhizal fungi (AMF) for the purpose of postindustrial bioremediation due to the divergence of their respective ecological and evolutionary stress-tolerance behaviors, attempts have been made (Juwarkar and Singh 2010; Audet 2013).

\section{Principle of bioremediation}

The main advantage of bioremediation is reducing the cost of remediation when compared to conventional techniques such as dredging (physical removal of the contaminated sediment layers), capping (covering the contaminated sediment surface with clean material, thus isolating the sediments) and incineration (waste treatment technology that involves the combustion of organic substances contained in waste materials). Bioremediation can be done on site, thus reducing exposure risks for cleanup personnel, or potentially wider exposure as a result of transportation accidents. Besides the above advantages, bioremediation is less expensive, eliminates waste permanently, eliminates long-term liability and can be coupled with physical or chemical treatment technologies. Furthermore, it is a non-invasive technique, leaving the ecosystem intact (Vidali 2001). However, it is not easy to predict the rate of cleanup for a bioremediation exercise as several environmental factors are involved in deciding the fate of bioremediation, and till date, scientists are in search of rules for predicting the rate of degradation of a contaminant in various components of the environment (Machackova et al. 2012).

\section{Factors affecting bioremediation}

Most important parameters for bioremediation are: (1) Nutrients-nutrients are not sufficient for cellular metabolism and growth of the microorganisms in the contaminated sites. Because, in the contaminated sites, organic carbons are high and these may be depleted during microbial metabolism. Thus, supplementing the nutrients such as nitrogen, phosphate and potassium to the contaminated site can stimulate the cellular metabolism and growth of the microorganisms which augment the bioremediation. The nutritional requirement of carbon-tonitrogen ratio $(\mathrm{C}: \mathrm{N})$ is 10:1, and carbon-to-phosphorous ratio is $30: 1$ for bioremediation. However, microbial growth for biodegradation occurred in contaminated soil with a much higher C:N (25:1) ratio (Atagana et al. 2003); (2) Nature of pollutants-pollutants are (a) solid, semi solid, liquid, volatile in nature, (b) toxic or non toxic organic and inorganic pollutants, (c) heavy metals, (d) polycyclic aromatic hydrocarbons, pesticides, chlorinated solvents, etc.; (3) Soil Structure-the soil structure contains different textures ranging from low to high contents of sand, silt and clay. A granular and wellstructured soil can facilitate effective delivery of air, water and nutrients to the microorganisms for in situ bioremediation; (4) $\mathrm{pH}-\mathrm{it}$ ranges from 5.5-8.0, which is the optimum range for the growth of microbes and to destroy the contaminants (Vidali 2001); (5) Moisture content-water is the primary factor in determining the dielectric constant of soil and other mediums. Soil moisture content generally ranges from 25 to $28 \%$ (Vidali 2001); (6) Microbial Diversity-the microbial diversity of the site such as Pseudomonas, Aeromonas, Flavobacteria, Chlorobacteria, Corynebacteria, Acinetobacter, Mycobacteria, Streptomyces, Bacilli, Arthrobacter, Aeromonas and Cyanobacteria, etc.; (7) Macrobenthos Diversity-consortium of aquatic plants E. crassipes, $S$. molesta, $C$. demersum with aquatic animals $A$. woodiana and $L$. hoffmeisteri have high potential to degradation of turbidity, BOD, COD, ammonia, nitrite and nitrate in domestic wastewater (Mangunwardoyo et al. 2013); (8) Temperature-it ranges from $15-45^{\circ} \mathrm{C}$. Temperature affects biochemical reaction rates and the rates are double for each $10{ }^{\circ} \mathrm{C}$ rise in temperature; and (9) Oxygen - it is mainly used for the initial breakdown of the hydrocarbon in the contaminated sites. Also, the amount of available oxygen will determine whether the bioremediation is carried out under aerobic or anaerobic condition (Thapa et al. 2012). It is the fact that although relevant knowledge has been gained in the field of bioremediation-through intensive laboratory researchthe exploitation of these innovations has not been fully realized (Ramos et al. 2011).

\section{Strategies for bioremediation}

Bioremediation is an option that offers the possibility to destroy or render harmless various contaminants using natural biological activity (Gupta and Mahapatra 2003). When bioremediation occurs on its own, it is known as natural attenuation; when it involves microorganisms along with added fertilizers, it is called biostimulation; when degradation takes place in the rhizosphere, it is known as rhizodegradation; when plants extract metals from soil and release them into the atmosphere by volatilization, it is known as phytovolatilization; when plant roots absorb or adsorb metals from aqueous solution, it is known as 
rhizofiltration; when seedlings absorb or adsorb pollutants from aqueous solution, it is known as blastofiltration; and when the pollutant is being immobilized in the root zone, it is known as phytostabilization. The combined rhizospheric (root zone) processes contributing to bioremediation have been termed as rhizoremediation (Prasad and Freitas 2003; Sarma 2011; Dhankher et al. 2011). Parallel utilization of different pollutants due to their flexible degradative capacity with microbial community is known as co-metabolism. Acclimatization, is an additional step, has been included to treat wastewater sludge in treatment plant. Introduction of genetically modified microorganisms (Paliwal et al. 2012) and metal-resistant marine bacteria (Poirier et al. 2013) can also be used as advance bioremediation techniques.

In general, the remediation technologies, whether in place or ex situ, do one of two things: They either remove the contaminants from the substratum (decontamination or cleanup techniques) or reduce the risk posed by the contaminants by reducing exposure (stabilization techniques) (Vangronsveld et al. 2009). The bioremediation process can be broadly categorized into two groups: in situ and ex situ bioremediation (Kensa 2011).

\section{In situ bioremediation}

In situ bioremediation involves supplying oxygen and nutrients by circulating aqueous solutions through contaminated soils to stimulate naturally occurring bacteria to degrade contaminants. It is a cheaper method which uses harmless microbial consortium to degrade the pollutants, especially useful for saturated soil and groundwater remediation. The technique includes conditions such as the infiltration of water containing nutrients and oxygen as electron acceptors (Vidali 2001; Chauhan and Jain 2010; Rayu et al. 2012).

Further, in situ bioremediation is broadly classified as 'intrinsic bioremediation' and 'engineered bioremediation' (Hazen 2010). The first approach deals with the stimulation of indigenously occurring microbial population by feeding them nutrients and oxygen to increase their metabolic activities. It is unmanipulated, unstimulated, unenhanced biological remediation of an environment, that is, biological natural attenuation of contaminants in the environment. The second approach involves any type of manipulated or stimulated or enhanced biological remediation of an environment (Hazen 2010). The introduction of specific microorganisms to the contaminated site accelerates the degradation process by generating or enhancing conducive physicochemical conditions (Kumar et al. 2011b). When site conditions are not suitable, engineered bioremediations are introduced to the particular site, especially using genetically engineered bacteria. It is assumed that free-living genetically engineered bacteria may have decreased level of survival due to the stress conditions imposed by both environment conditions as well as introduced foreign genes. Therefore, choosing and engineering the bacterial strain with rapid growth potential having more effective bioremediation potential without environmental risk will be a crucial step for achieving a safe and sustainable environment (Singh et al. 2011).

The major advantages of in situ bioremediation are costeffectiveness, having no excavation, minimal site disruption, minimal dust production, and the possibility of simultaneous treatments of soil and groundwater in future. However, the major drawbacks are time-consuming, seasonal variation in the microbial activity and problematic application of treatment additives in the natural environment. Besides these, in situ bioremediation may become uncontrollable as well as less manageable under few circumstances. In such cases, either ex situ bioremediation is preferred or genetically engineered microorganisms have to be used; although stimulating indigenous microorganisms is preferred (Rayu et al. 2012).

\section{Ex situ bioremediation}

Ex situ bioremediation techniques involve the excavation or removal of contaminated soil/water from the ground. The method is broadly classified as solid phase system (including land treatment and soil piles) and slurry phase systems (including solid liquid suspensions in bioreactors). Solid phase treatment includes organic wastes (leaves, manures and agricultural wastes) and problematic wastes, for example domestic/industrial wastes and sewage sludge/ municipal solid wastes. The treatment processes include soil biopiles, composting, land farming and hydroponics (Ramos et al. 2011; Kumar et al. 2011b; Rayu et al. 2012). A biopile is a short-term bioremediation technology in which excavated soils are mixed with soil amendments, formed into compost piles or cells aboveground and enclosed for treatment supported with aeration system $(\mathrm{Li}$ et al. 2004). Biopiles, hybrid of land farming and composting, provide a favorable environment for indigenous aerobic and anaerobic microorganisms. Engineered cells are constructed as aerated composted piles, typically used for the treatment of surface contaminants that tend to control physical losses of the contaminants by leaching and volatilization. Under slurry phase bioremediation, a more rapid process, contaminated soil combines with water and other additives in a large tank called a bioreactor and mixed to keep the microorganisms in contact with the contaminants in the soil to create the optimum environment for the microorganisms to degrade the contaminants. By ensuring proper sampling techniques and maintaining controlled conditions with collected core sample, the effective ex situ bioremediation can be achieved (Paliwal et al. 2012). A pilot study of 6 months of biopile farming confirmed that bioaugmentation and 
biostimulation could enhance the bioremediation of petroleum-contaminated soil (Cheng et al. 2009). The optimum proportion of cattle manure enhanced organic matter degradation and humification process; consequently it reduced the toxicity of metals during rotary drum composting (Singh and Kalamdhad 2013) while evaluating the bioavailability of heavy metals $(\mathrm{Zn}, \mathrm{Cu}$, $\mathrm{Mn}, \mathrm{Fe}, \mathrm{Ni}, \mathrm{Pb}, \mathrm{Cd}$ and $\mathrm{Cr}$ ) using water hyacinth (Eichhornia crassipes). Application of composts release available nutrients and energy into the surroundings, especially for microbial activity increasing the zone of influence from the compost-soil interface (Duong et al. 2013). Land farming is a simple technique in which contaminated soil is excavated and spread over a prepared bed and periodically tilled until pollutants are degraded through stimulation of indigenous biodegradative microorganisms; and the practice is limited to the treatment of superficial $10-35 \mathrm{~cm}$ of soil. Composting involves combining contaminated soil with organic amendments such as manure or agricultural wastes. The presence of these organic materials supports the development of a rich microbial population (Paliwal et al. 2012). Hydroponics is a method of growing plants using mineral nutrient solutions in water. Now it has become a common method for the characterization of plant response to metal stress/exposure, as a basic step to select plant species for phytoremediation. For effective bioremediation through hydroponics, this method is integrated with other remedial techniques. A wastewater treatment plant using conventional biological treatment combined with hydroponics and microalgae was constructed in a greenhouse in the area of Stockholm, Sweden (Norstrom et al. 2004). A microalgal step further reduced phosphorus, and a final sand filter polished the water. Nitrification and denitrification was well established with total nitrogen reduction of $72 \%$, phosphorus by $47 \%$ and COD by $90 \%$ in the process. Recently, Iori et al. (2013) evaluated the morphophysiological responses, such as biomass production and partitioning, nickel accumulation in plants and nickel removal ability by growing 3-week-old Amaranthus paniculatus L. plants, subjected to nickel chloride concentrations of 0 (control), 25, 50, 100 and $150 \mu \mathrm{M}$, in hydroponic solution for 1 week and observed almost $60 \% \mathrm{Ni}$ removal efficiency showing no stress symptoms by the plants.

In general, the rate and extent of biodegradation are greater in a bioreactor system than in situ because the contained environment is more manageable and hence more controllable and predictable. The major drawback of this system is that the contaminant can be stripped from the soil via soil washing or physical extraction before being placed in a bioreactor.

The occurrence of some other bioremediation methods is also described below.

\section{Bioventing}

It is the most common in situ treatment and involves supplying air and nutrients through wells to a contaminated soil to stimulate the indigenous aerobic bacteria and is an example of sub-surface bioremediation. It employs low air flow rates and provides only the amount of oxygen necessary for the biodegradation while minimizing volatilization and release of contaminants to the atmosphere. Typically, pollutants are biodegraded in aerobic conditions by indigenous heterotrophic microorganisms naturally occurring in the soil or sub-surface soil. But, in order to promote microbial degradation, air or poor oxygen is delivered to anaerobic and permeable polluted soil profiles at a low flow rate so that the oxygen supply rate meets the demand by the microbes and minimizes volatilization of pollutants (USEPA 2004). Subsurface bioremediation remediates shallow aquifers through geochemical reactions (including the redox potential and dynamics of heavy metal adsorption), which ultimately leads to remediate soils from heavy metals, and it also provides safe groundwater for drinking and irrigation purposes (Robinson et al. 2011).

\section{Biosparging}

It involves the injection of air under pressure below the water table to increase groundwater oxygen concentrations and enhance the rate of biological degradation of contaminants by naturally occurring bacteria (Adams and Reddy 2003). It increases the mixing in the saturated zone and thereby increases the contact between soil and groundwater. The ease and low cost of installing small diameter air injection points allows considerable flexibility in the design and construction of the system. Biosparging can be used to reduce the concentration of petroleum constituents that are dissolved in groundwater, adsorbed to soil below the water table and within the capillary fringe. It is very effective in reducing petroleum products at underground storage tank sites (USEPA 2004). However, almost similar phenomena in this method are involved in the remediation of soils from heavy metals as in the case of bioventing.

A biosparging system was designed and applied to a cocontaminated arsenic-hydrocarbon aquifer at oilfield services facilities, Odessa, Texas, USA, during 1997-2001 (Cooley et al. 2009). The optimal dosage of injection of soybased methyl ester (SME) solution effectively treated the cocontaminated aquifer, without increasing the BOD to the point where overly reducing conditions in the aquifer would potentially disturb current decreasing benzene and arsenic concentration trends. The remediation of large-scale petroleum contamination of soil and groundwater has provided valuable information about biosparging 
efficiency in the sandstone sedimentary bedrock (Machackova et al. 2012; Kumar and Mani 2012). The nutrient structures control the biosparging pressure and distribution of oxygen and nutrients in the saturated zone. For example, fine-grained soils require higher sparging air pressures because air flow is restricted through smaller pores. Temperature is another important factor as bacterial growth rate is a function of temperature. The optimum $\mathrm{pH}$ for bacterial growth is approximately 7 , and the acceptable range for biosparging is between 6 and 8. Among diverse microorganisms, the bacteria are the most numerous and biochemically active group particularly at low oxygen levels. The population density of naturally occurring bacteria also contributes to the degradation of petroleum constituents. Plate count results are normally reported in terms of colony-forming units (CFUs) per gram of soil for biosparging. Microbial population densities in typical soils range from $10^{4}$ to $10^{7} \mathrm{CFU} / \mathrm{gram}$ of soil. The presence of ferrous iron (dissolved $\mathrm{Fe}^{+2}$ ) in groundwater also reduces the permeability of the saturated zone soils during the sparging operations.

Biosparging was applied as an innovative cleanup technology at the site and was operated over a 10-year period (1997-2008) at the former Soviet Army air base in the Czech Republic (Machackova et al. 2012). An overall rise in average groundwater temperature was observed in the cleanup fields, most probably as a result of the biological activity during the cleanup process. The significant rise in biodegradation rates, observed after air sparging intensification, and strong linear correlation between the air injection rates and biodegradation activities have shown that the air injection rate is the principal factor in biodegradation efficiency in heavily contaminated areas (Machackova et al. 2012).

\section{Bioaugmentation}

Bioaugmentation is the addition of pre-grown microbial cultures indigenous or exogenous to the contaminated sites to enhance the degradation of unwanted compounds (Tyagi et al. 2011). Exogenous cultures rarely compete well enough with an indigenous population to develop and sustain useful population levels, and most soils with long-term exposure to biodegradable waste have indigenous microorganisms that are effectively degraded if the land treatment unit is well managed (USEPA 2004; Kumar et al. 2011b).

In general, like other bioremediation processes, bioaugmentation may not stand alone at its own. The combined bioaugmentation and biostimulation along with degrading bacteria, biosurfactants, organic carbon source with kitchen waste or compost along with nutrient enhancement (like $\mathrm{NH}_{4} \mathrm{NO}_{3}, \mathrm{~K}_{2} \mathrm{HPO}_{4}$ ) at maintaining around $15-25 \%$ moisture content and $30 \pm 2{ }^{\circ} \mathrm{C}$ temperature produced better results (Cheng et al. 2009).

\section{Biodegradation}

It is a generic term used to describe the methodologies affecting cleanup of environmental pollutants. It has become as an improved substitute for ineffective and expensive physicochemical remediation methods. However, lack of information about the growth and metabolism of microorganisms in the polluted environment often limits its implementation. Recent advances in the understanding of biogeochemical processes and genomics have opened up new perspectives toward new opportunities of pollution abatement (Chauhan and Jain 2010; Jeffries et al. 2012; Rayu et al. 2012; Tyagi et al. 2011). In order for considerable aerobic biodegradation to occur, however, sufficient amounts of dissolved oxygen must exist within the subsurface to serve as an electron acceptor (Adams and Reddy 2003).

The drawbacks of even the current bioremediation techniques have made it necessary to seek more eco-friendly and cost-effective techniques for heavy metals-contaminated sites. Microbially induced calcite precipitation (MICP) provides alternative way to solve these problems. The MICP products are able to strongly adsorb heavy metals on their surfaces. During precipitation of calcite, heavy metal ions with ion radius close to $\mathrm{Ca}^{2+}$, such as $\mathrm{Cd}^{2+}, \mathrm{Pb}^{2+}, \mathrm{Sr}^{2+}$ and $\mathrm{Cu}^{2+}$, may be incorporated into the calcite crystal by substitution reaction (Pan 2009). An indigenous calcifying bacterial strain Kocuria flava CR1 was isolated from a mining area, Urumqi, China (Achal et al. 2011). Based on MICP process, the isolate removed $95 \%$ of copper from the contaminated site; hence, the ability of $K$. flava was first time documented as a viable and eco-friendly technology for remediation of $\mathrm{Cu}$-contaminated site.

\section{Application of bioremediation}

Bioremediation has potential to restore contaminated environments (Dowarah et al. 2009) inexpressively get effectively, but a lack of information about the factors controlling the growth and metabolism (Li et al. 2013) of microorganism in polluted environments often limits its implementation. Bioinformatics, based on proteomics and genomics (Chauhan and Jain 2010; Poirier et al. 2013), offers remarkable promise as tools to address longstanding questions regarding the molecular mechanisms involved in the control of mineralization pathways (Kim and Park 2013; Govarthanan et al. 2013; Achal et al. 2012b). Using a proteomics approach, the physiological changes in an organism during bioremediation provide further insight into bioremediation related genes and their regulation.

Bio-/phytoremediation and non-biological remediation technologies are not mutually exclusive because pollutant 
distribution and concentration are heterogeneous for many sites. The most efficient and cost-effective remediation solution may be a combination of different technologies, such as evaluating the degree of contamination through designed biosensors (Checa et al. 2012), excavation of the most contaminated spots, designing geohydrobiological engineering models (Sivakumar 2012), followed by polishing the site using microbe-assisted plants (Pilon-Smits 2005; Juwarkar et al. 2009; Juwarkar and Singh 2010). The integrative effort may prove to be one of the best environmental practices for the reclamation of degraded lands.

Guo et al. (2010) isolated a multi-metal-resistant endophytic bacterium L14 (EB L14) from the cadmium hyperaccumulator Solanum nigrum L. The excellent adaptation abilities and promising remediation efficiencies strongly indicated the superiority of this endophyte in heavy metals [Cd(II), $\mathrm{Pb}(\mathrm{II})$ and $\mathrm{Cu}(\mathrm{II})]$ bioremediation at the initial concentration of $10 \mathrm{mg} / \mathrm{l}$ with excellent adaptation abilities and promising remediation efficiency for heavy metals bioremediation, which could be useful for developing efficient metal removal systems. Composted olive husk using Beta maritima L. as an indicator species (de la Fuente et al. 2011) and humic substances using Helianthus annuus L. (Jadia and Fulekar 2008; Mani et al. 2012b) have been proven to be an appropriate material for the development of bioremediation strategies on a metal-polluted soil.

\section{Mycoremediation}

Mycoremediation (coined by Stamets), a form of bioremediation, is the process of using fungi to degrade or sequester contaminants in the environment, to repair or restore the weakened immune system of environment. Mycofiltration, also a similar process, uses fungal mycelia to filter toxic waste and microorganisms from water in the soil, through stimulation of microbial and enzyme activity. The saprophytic, endophytic and mycorrhizal fungi are capable of recovering the soil-water ecosystems and balancing biological population. The mycelium secretes extracellular enzymes and acids that break down lignin and cellulose, the two main building blocks of plant fiber. The key to mycoremediation is determining the right fungal species to target a specific pollutant (Stamets 2005). Dudhane et al. (2012) reported a major role of mycorrhizal fungi in bioremediation through secretion of glomaline (one of the glycoprotein), which stabilized the aluminum in soil as well as in the roots of Gmelina plants.

Fungal species such as Aspergillus niger, Aureobasidium pullulans, Cladosporium resinae, Funalia trogii, Ganoderma lucidum, Penicillium spp. (Loukidou et al. 2003; Say et al. 2003), Rhizopus arrhizus and Trametes versicolor are capable of recovering heavy metals from the polluted environment. Taştan et al.
(2010) investigated the bioaccumulation potential of Aspergillus versicolor for heavy metal which was maximum at optimal $\mathrm{pH}$ values as 6 for $50 \mathrm{mg} / \mathrm{L} \mathrm{Cr}(\mathrm{VI})$, $\mathrm{Ni}(\mathrm{II})$ and 5 for $\mathrm{Cu}(\mathrm{II})$ ions with the $99.89,30.05$ and $29.06 \%$ removal yield, respectively. The result indicated that $A$. versicolor strain deserves attention as a promising bioaccumulator of chromium ions in wastewater effluents. Further, Ramasamy et al. (2011) found the fungal strain (Aspergillus fumigates) suitable for removing $\mathrm{Pb}(\mathrm{II})$ ions from the aqueous solution of electronic waste (containing $\mathrm{Pb} 100 \mathrm{mg} / \mathrm{L}$ ) and reported its maximum adsorption of $85.41 \%$ during the batch sorption experiment. In a micellar-enhanced ultrafiltration (MEUF) of phosphorousrich wastewater, Zeftawy and Mulligan (2011) reported that MEUF could treat heavy metals with rejection ratios of $>99 \%$ at an optimal MEUF condition at biosurfactant-tometal molar ratios of 2:1, a transmembrane pressure of $69 \mathrm{kPa}$, at $25^{\circ} \mathrm{C}$ and $\mathrm{pH}$ 6.9. Häyrynen et al. (2012) observed a statistically significant effect of pressure and cross-flow velocity on the flux and achieved significant heavy metals $(\mathrm{Cd}$ and $\mathrm{Cu})$ rejection coefficients (Landaburu-Aguirre et al. 2012), while P was not retained. Thus, potential application of novel MEUF for purification of nutrient-rich wastewaters has been recently justified. The recent advances regarding mycoremediation have been highlighted under Table 1 .

\section{Cyanoremediation}

The rate of influx of heavy metals $(\mathrm{Cd}, \mathrm{Ni}, \mathrm{V})$ into the atmosphere far exceeds their elimination by natural processes, consequently leading to the accumulation of heavy metals in the marine ecosystem at the receiving end (Shirdam et al. 2006). Several living and non-living microorganisms such as bacteria, microalgae (Norstrom et al. 2004), green algae (Deng et al. 2007; Singhal et al. 2004) and blue-green algae (Tripathi et al. 2008; Yin et al. 2012) have been found suitable for the treatment of contaminated aquatic ecosystem. Recently, there has been increasing awareness about cyanoremediation (use of cyanobacteria to remediate heavy metals) as bioremediation and pollution control agents, either as wild type, mutant or genetically engineered forms (Yin et al. 2012). Synechocysis sp. PCC6803, a unicellular blue alga, accumulated arsenic as much as 1.0 and $0.9 \mathrm{~g} / \mathrm{kg} \mathrm{DW}$ when exposed to $0.5 \mathrm{mM}$ arsenate and arsenite for 14 days, respectively. When treated with $2.67 \mu \mathrm{M}$ arsenite, Synechocysis rapidly oxidized arsenite to arsenate and accumulated As rapidly through cellular oxidation (Yin et al. 2012). The robust ability of the blue algae for As accumulation can serve as cyanoremediation to efficiently remove arsenic from aquatic environments. Although the role of cyanobacteria has been established for remediation 
Table 1 Some microbes having bioremediation (cyanoremediation, biostimulation, mycoremediation) potential and heavy metals they can remediate

\begin{tabular}{|c|c|c|c|c|}
\hline S. No. & Microbes & Species & Metals & References \\
\hline 1. & \multirow[t]{8}{*}{ Algae } & Chlorella pyrendoidosa & $\mathrm{U}$ & Singhal et al. (2004) \\
\hline 2. & & $\begin{array}{l}\text { Aspergillus niger, Ascophyllum nodosum, } \\
\text { Bacillus firmus, Chlorella fusca, } \\
\text { Oscillatoria anguistissima }\end{array}$ & $\mathrm{Pb}, \mathrm{Zn}, \mathrm{Cd}, \mathrm{Cr}, \mathrm{Cu}, \mathrm{Ni}$ & Ahluwalia and Goyal (2007) \\
\hline 3. & & Cladophora fascicularis & $\mathrm{Pb}$ & Deng et al. (2007) \\
\hline 4. & & Saccharomyces cerevisiae & $\mathrm{Cr}, \mathrm{Ni}, \mathrm{Cu}, \mathrm{Zn}$ & Machado et al. (2010) \\
\hline 5. & & Spirogyra sp. and Cladophora sp. & $\mathrm{Pb}, \mathrm{Cu}$ & Lee and Chang (2011) \\
\hline 6. & & Spirogyra sp. and Spirullina sp. & $\mathrm{Cr}, \mathrm{Cu}, \mathrm{Fe}, \mathrm{Mn}, \mathrm{Zn}$ & Mane and Bhosle (2012) \\
\hline 7. & & $\begin{array}{l}\text { Hydrodictylon, Oedogonium and Rhizoclonium } \\
\text { species }\end{array}$ & $\mathrm{V}$, As & Saunders et al. (2012) \\
\hline 8. & & Spirogyra sp. and Spirulina sp. & $\mathrm{Cr}, \mathrm{Cu}, \mathrm{Fe}, \mathrm{Mn}, \mathrm{Se}, \mathrm{Zn}$ & Mane and Bhosle (2012) \\
\hline 9. & \multirow[t]{14}{*}{ Bacteria } & Pseudomonas veronii & $\mathrm{Cd}, \mathrm{Zn}, \mathrm{Cu}$ & Vullo et al. (2008) \\
\hline 10. & & Burkholderia species & $\mathrm{Cd}, \mathrm{Pb}$ & Jiang et al. (2008) \\
\hline 11. & & Bacillus and Pseudomonas & $\mathrm{U}$ & Kumar et al. (2008b) \\
\hline 12. & & Bradyrhizobium sp. and Rhizobacteria sp. & $\mathrm{Cd}, \mathrm{Pb}, \mathrm{Cu}$ & Dary et al. (2010) \\
\hline 13. & & Bacillus sp. & $\mathrm{Cd}, \mathrm{Pb}, \mathrm{Cu}$ & Guo et al. (2010) \\
\hline 14. & & Kocuria flava & $\mathrm{Cu}$ & Achal et al. (2011) \\
\hline 15. & & Serratia marcescens & $\mathrm{U}$ & Kumar et al. $(2011 \mathrm{a}, \mathrm{b})$ \\
\hline 16. & & Pseudomonas aeruginosa & $\mathrm{U}$ & Choudhary and Sar (2011) \\
\hline 17. & & Bacillus cereus & $\mathrm{Cd}, \mathrm{Zn}$ & Hrynkiewicz et al. (2012) \\
\hline 18. & & Bacillus cereus & $\mathrm{Cr}$ & Kanmani et al. (2012) \\
\hline 19. & & Halomonas sp. & $\mathrm{Sr}$ & Achal et al. (2012a) \\
\hline 20. & & Sporosarcina ginsengisoli & As & Achal et al. (2012b) \\
\hline 21. & & $\begin{array}{l}\text { Species of Bacillus, Streptococci, Salmonella, } \\
\text { Pseudonomnas, Micrococcus and E. coli }\end{array}$ & $\mathrm{Cd}, \mathrm{Cu}, \mathrm{Fe}$ & Fulekar et al. (2012) \\
\hline 22. & & Bacillus cereus strain XMCr-6 & $\mathrm{Cr}$ & Dong et al. (2013) \\
\hline 23. & \multirow[t]{6}{*}{ Fungi } & Penicillium canescens & $\mathrm{Cr}$ & Say et al. (2003) \\
\hline 24. & & Ganoderma lucidum, Penicillium sp. & $\mathrm{Ar}$ & Loukidou et al. (2003) \\
\hline 25. & & Aspergillus versicolor & $\mathrm{Cr}, \mathrm{Ni}, \mathrm{Cu}$ & Tastan et al. (2010) \\
\hline 26. & & Aspergillus fumigatus & $\mathrm{Pb}$ & Ramasamy et al. (2011) \\
\hline 27. & & Cladonia rangiformis (lichen) & $\mathrm{Pb}$ & Ekmekyapar et al. (2012) \\
\hline 28. & & $\begin{array}{l}\text { Species of Aspergillus, Mucor, } \\
\text { Penicillium and Rhizopus }\end{array}$ & $\mathrm{Cd}, \mathrm{Cu}, \mathrm{Fe}$ & Fulekar et al. (2012) \\
\hline
\end{tabular}

of aquatic and wetland ecosystems (Fiset et al. 2008) and of agricultural rice fields (Tripathi et al. 2008) for metals recovery through seaweeds including Anabaena spp., Nostoc spp. Oscillatoria spp., Calothrix spp. and Synechoccus spp., yet the beneficial application of cyanobacteria in remediation of contaminated natural aquatic environments or industrial effluents has still not been optimally defined (Fiset et al. 2008).

Deng et al. (2007) observed that the green marine algae Cladophora fascicularis can be used as an efficient biosorbent material for removal of $\mathrm{Pb}$ (II) from wastewater (as a function of time, initial $\mathrm{pH}$, initial $\mathrm{Pb}$ (II) concentrations, temperature and co-existing ions). Further, Dubey et al. (2011) evaluated the potential of cyanobacterial species (Oscillatoria sp., Synechococcus sp., Nodularia sp., Nostoc sp. and Cyanothece sp.), which were found suitable for bioremediation, especially in biodegradation and biosorption of contaminants (ammonia, nitrate), either as individuals or mixtures, and the contaminants removal efficiency (RE) percentage of cyanobacterial species ranged from 69.5 to $99.6 \%$, while the mixed culture RE percentages ranged from 91.6 to $100 \%$, at $5 \mathrm{ppm}$ concentration of the pollutants. Lee and Chang (2011) evaluated the potential biosorption capacity of the green algae species, Spirogyra and Cladophora, for lead $\left(\mathrm{Pb}^{2+}\right)$ and copper $\left(\mathrm{Cu}^{2+}\right)$ from aqueous solutions. The highest percent bioremoval was observed by Spirogyra $\mathrm{sp}$. for $\mathrm{Cr}(98.23 \%), \mathrm{Cu}(89.6 \%), \mathrm{Fe}(99.73 \%), \mathrm{Mn}(99.6 \%)$, 
Se $(98.16 \%)$ and $\mathrm{Zn}(81.53 \%)$ and the same by Spirulina sp. for $\mathrm{Cr}(98.3 \%), \mathrm{Cu}(81.2 \%), \mathrm{Fe}(98.93 \%), \mathrm{Mn}(99.73 \%)$, Se $(98.83 \%)$ and $\mathrm{Zn}(79 \%)$, at $5 \mathrm{mg} / \mathrm{L}$ initial metal concentration (Mane and Bhosle 2012). Recently, Saunders et al. (2012) cultured three species of algae (Hydrodictylon, Oedogonium and Rhizoclonium species) to test its metal uptake and bioremediation potential in wastewater contaminated with heavy metals derived from coal-fired power generation. All species achieved high concentrations of heavy metals (to $8 \%$ dry mass) and especially vanadium and arsenic concentration reached remarkably up to 1,543 and $137 \mathrm{mg} / \mathrm{kg}$ DW, respectively. Thus, algae have been proven as efficient biological vectors having a beneficial role in the practical application of wastewater bioremediation. The recent advances regarding cyanoremediation have been highlighted under Table 1.

\section{Biostimulation}

Microorganisms, especially bacteria and fungi, are nature's original recyclers. Their capability to transform natural and synthetic chemicals into sources of energy (Tang et al. 2007) and raw materials for their own growth suggests that expensive chemical or physical remediation processes should be replaced by biological processes that are lower in cost and more environmentally friendly. Injection of nutrients and other supplementary components to the native microbial population to induce propagation at a hastened rate (biostimulation) is one of the most common approaches for in situ bioremediation of accidental spills and chronically contaminated sites worldwide (Cheng et al. 2009; Tyagi et al. 2011). Biostimulation activity through microbe is stimulated by supplementing nutrients (nitrogen and phosphorus), electron acceptors (oxygen), and substrates (methane, phenol and toluene), or introducing microorganisms with desired catalytic capabilities (Ma et al. 2007; Baldwin et al. 2008).

Recently, Kanmani et al. (2012) reviewed chromium bioremediation and outlined heterogeneous group of bacteria isolated from contaminated sites to remediate chromium. These bacteria exhibit plasmid-mediated chromate resistance and the reduction is enzymatically mediated. With molecular engineering, now it may be possible to derive strains with improved performance even under stressful field conditions. Kiyono et al. (2012) isolated bacterial merC gene (a potential molecular tool) for improving the efficiency of cadmium phytoremediation. Arabidopsis thaliana protein receptors including SYP111/ SYP121 and SYP22 attached to the C-terminus of MerC and targeted foreign molecules to the plasma membrane and vacuolar membrane, respectively. The transgenic plants expressing merC-SYP121 were more resistant to cadmium than the wild type and accumulated significantly more cadmium, which indicated an ecologically compatible approach for the phytoremediation of cadmium pollution. Fulekar et al. (2012) investigated bioremediation potential of biostimulated microbial culture isolated from heavy metals waste disposal contaminated site located at Bhayander, Mumbai, India. The microbial consortium has been found effective for remediation of $\mathrm{Cd}$, $\mathrm{Cu}$ and $\mathrm{Fe}$ at higher concentration, that is, $100 \mathrm{mg} / \mathrm{L}$ up to 98.5, 99.6 and $100 \%$, respectively.

A column reactor was inoculated with sulfate-reducing bacteria (SRB) and fed with a solution containing sulfate and heavy metals $\left(\mathrm{As}^{\mathrm{V}}, \mathrm{Cd}, \mathrm{Cr}^{\mathrm{VI}}, \mathrm{Cu}\right.$ and $\left.\mathrm{Zn}\right)$; sulfate abatement was $50 \pm 10 \%$, while metals were totally removed (Viggi et al. 2010). Recently Pagnanelli et al. (2012) reported reduction in synthetic acid mine drainage toxicity by using the nematode Caenorhabditis elegans. The survival of nematodes was $20 \%$ in the presence of the untreated effluent ( $\mathrm{Cr}$ contaminated water) and raised up to $53 \%$ when the nematodes were exposed to the SRBtreated effluent. Some recent developments regarding biostimulation have been highlighted under Table 1 .

Although significant progress has been made, much needs to be done for its success during in situ application as the organism may not withstand at the higher metal concentration or may be impeded by the presence of other toxicants (Kanmani et al. 2012). The possibility of metal recovery biostimulation is also negligible. In such cases, biosorption may be preferred.

\section{Biomineralization}

Mining activities are a major source of heavy metal contamination in the ecosystem. Several studies have reported elevated levels of metals around metalliferous mines and industrial area. The resulting contamination of nearby agriculture soils and streams is among the current environmental concerns. Metalliferous soils provide very restrictive habitats for plants due to phytotoxicity, resulting in severe selection pressures. Species comprising heavy metal plant communities are genetically altered ecotypes with specific tolerance to, for example, cadmium, copper, lead, nickel, zinc and arsenic, adapted through microevolutionary processes. Evolution of metal tolerance takes place at each specific site (Ernst 2006). A high degree of metal tolerance depends on the bioavailable fraction of the metalloids in soil and the type of mineralization.

The synthesis of materials resembling complex morphology of natural biominerals is one of key fields in biomimetic science. Biomineralization is a natural pathway of producing complicated structured inorganic materials that possess vital functions in biological systems. The diverse morphologies of biominerals have motivated scientists to mimic these materials through the underlying 
chemistry of biomineralization, which has enabled the replication of the outstanding mechanical and optical properties of biominerals with their unique biological functions, such as navigation, storage and homeostasis (Mann 2001; Kim and Park 2013).

Nature provides spectacular examples of biologically formed minerals (biomineralization) such as mesoporous silica nanoparticles (MSPs), which have emerged as appealing carriers for controlled anticancer drug delivery owing to their low toxicity, high surface area and large accessible pore volumes (Kim et al. 2010). Now, novel methods of biomineralization are being discovered (Achal et al. 2012b; Chen et al. 2013) to construct organic-inorganic hybrid for highly toxic elements. Achal et al. (2012b) established the versatility of Sporosarcina ginsengisoli CR5, capable of tolerating high concentration of arsenic [50 $\mathrm{mM} \mathrm{As(III)]} \mathrm{and}$ which produced significant amount (urease activity-412 $\mathrm{U} / \mathrm{ml}$ ) of urease, a calcite-precipitating enzyme. They discovered the bioremediation potential of the bacterium, which will be a milestone for recovering As contamination across the globe.

Chen et al. (2013) prepared MSPs by utilizing hyaluronic acid (HA) as a reaction site for deposition of calcium phosphate $(\mathrm{CaP})$ minerals. Microbial processes that bind metals and form minerals represent a fundamental part of key biogeochemical cycles which can mediate the formation of minerals by mineralization. The process offers an efficient way to sequester heavy metals within relatively stable solid phases. Recently Li et al. (2013) investigated the mechanisms involved in mineral precipitation through urease-producing bacteria for their potential application in bioremediation. Due to enzymatic reaction of urease, soil $\mathrm{pH}$ increased and carbonate was produced, which resulted in mineralization of heavy metals ions which deposited around the cell envelope when the $\mathrm{pH}$ was 8-9. X-ray diffraction studies conducted in South Korea confirmed the role of bacterially induced calcite precipitation in the bioremediation of $\mathrm{Pb}$ in mine tailings (Govarthanan et al. 2013). An isolate KK1 exhibited maximum $\mathrm{Pb}$ resistance and was subsequently identified as Bacillus sp. based on the partial 16S rRNA gene sequences which reduced the $\mathrm{Pb}$ ions. Selective sequential extraction of bioaugmented soil revealed that the isolate significantly reduced $(26 \%)$ the exchangeable fraction and increased (38\%) the carbonate fraction of $\mathrm{Pb}$. A significant increase in the urease (334\%), DHO (dehydrogenase) (14\%) and phosphatase (37\%) activity was observed in the bioaugmented mine soil (Govarthanan et al. 2013).

\section{Biosorption}

Biosorbents, the passive uptake of pollutants by biological materials, especially derived from seaweed, green macroalgae and alginate derivatives, exhibit high affinity for many metal ions. It is emerging as a potential alternative to the existing conventional technologies for the removal and/or recovery of metal ions from aqueous solutions (Schiewer and Patil 2008). The major advantages of biosorption over conventional treatment methods include low cost, high efficiency, minimization of chemical or biological sludge, regeneration of biosorbents and possibility of metal recovery (Azouaou et al. 2008; Sud et al. 2008).

Biosorbents are widely abundant, usually biodegradable and less expensive than industrial synthetic adsorbents and hold great potential for the removal of toxic metals from industrial effluents (Fiset et al. 2008). These results helped in the derivation of the order of the sorption capacity of metal ions. Ahluwalia and Goyal (2007) investigated an innovative and alternative technology for removal of heavy metals $(\mathrm{Pb}, \mathrm{Zn}, \mathrm{Cd}, \mathrm{Cr}, \mathrm{Cu}$ and $\mathrm{Ni}$ ) from aqueous solution by metabolically inactive biomass of Aspergillus Niger, Ascophyllum nodosum, Bacillus firmus, Chlorella fusca, Oscillatoria anguistissima, Penicillium chrysogenum, Rhizopus nigricans, Sargassum natans and Streptomyces sp. for metal adsorption capacities ranging from 5 to $641 \mathrm{mg} / \mathrm{g}$. These studies indicate that biomass generated as a by-product of fermentative processes offers great potential for adopting an economical metal recovery system. However, the ability to recover heavy metals from biosorbents without destroying their sorption capability is also crucial (Lesmana et al. 2009) and heavy metals can be recovered quite easily, although in several cases, the metal binding capability deteriorates after regeneration (Abdel-Ghani et al. 2007).

Machado et al. (2010) examined the biosorption of metal ions by yeast cells of Saccharomyces cerevisiae (12 $\mathrm{g}$ dry weight $\mathrm{L}^{-1}$ of yeast cells) and found that concentration of nickel in the real effluent $(34 \mu \mathrm{mol} / \mathrm{L})$ reached under the quality criteria for industrial effluent discharge, leading to removal of nickel up to $89 \%$. Tokuyama et al. (2010) developed an enhanced metal separation technique [a model system consisting of metal ions $\left(\mathrm{Cu}^{2+}\right.$ or $\left.\mathrm{Cr}^{3+}\right)$, humic acid (HA) and thermosensitive $\mathrm{N}$-isopropylacrylamide (NIPA) polymer] for the coadsorption of undesirable heavy metals and humic substances in water and soil environments. The reusable grafted polymer can permit temperature-swing adsorption and provide an eco-friendly metal separation process.

Dubey and Shiwani (2012) established the potential of Portulaca oleracea as a potential low-cost adsorbent for removal of lead ions from water. Jiang et al. (2012b) applied biochar as an amendment to the ultisol leading to remarkable improvement in soil $\mathrm{pH}$ and marked reduction in the acid soluble $\mathrm{Cu}$ (II) and $\mathrm{Pb}$ (II) after addition of biochar. Najafi et al. (2012) synthesized novel amino 
functionalized silica nano-hollow sphere (adsorbent) for removal of heavy metal ions and reported decreasing adsorption tendency of ions in the order of $\mathrm{Pb}(\mathrm{II})>$ Cd(II) > Ni(II). Ekmekyapar et al. (2012) reported a lichen (Cladonia rangiformis Hoffm) as a suitable biosorbent for removing $\mathrm{Pb}(\mathrm{II})$ from aqueous solutions.

\section{Bioremediation of multi-metal waste sites/radionuclides}

Multidisciplinary studies have been commenced to evaluate the impact of nuclear waste on the sub-surface environment and to utilize the resources adapting in such environment for the use as potential remediation tools. Since 1978, the Maryland Department of Natural Resources has investigated the uptake and depuration by Crassostrea ariakensis (Fujita 1913) and Crassostrea virginica (Gmelin 1791) in the discharge area of a nuclear power plant in central Chesapeake Bay in southern Maryland, USA (Mclean and Abbe 2008). They compared radionuclide transfer dynamics and other parameters such as growth, mortality, disease status and meat condition in a side-by-side, in situ environmental setting. Although quantities of radionuclides like $\mathrm{Co}^{58}$, $\mathrm{Co}^{60}$ or $\mathrm{Ag}^{110}$ were insufficient to produce detectable concentrations in either species, the findings would provide positive signal for $C$. ariakensis in multi-metal waste sites/ radionuclide (Mclean and Abbe 2008). Tits et al. (2008) investigated the immobilization of $\mathrm{U}(\mathrm{VI})$ by $\mathrm{C}-\mathrm{S}-\mathrm{H}$ phases near field of a repository for radioactive waste in Japan. They proposed that a solid solution containing $\mathrm{Ca}$ and $\left(\mathrm{UO}^{2+}\right)_{2}$ could control $\mathrm{U}(\mathrm{VI})$ uptake by $\mathrm{C}-\mathrm{S}-\mathrm{H}$ phases. Screening for multi-metal-resistant bacterial isolates is ongoing. For example, Vullo et al. (2008) isolated bacteria which were resistant to both $\mathrm{Zn}$ and Cd. Chikere et al. (2012) reported bioreactor-based bioremediation of hydrocarbonpolluted marine sediments biostimulated with either $\mathrm{K}_{2} \mathrm{HPO}_{4}$, $\mathrm{NH}_{4} \mathrm{NO}_{3},\left(\mathrm{NH}_{4}\right)_{2} \mathrm{SO}_{4}, \mathrm{NPK}$, urea or poultry droppings across the Bonny river, Port Harcourt, Nigeria.

Radionuclides enter the soil and water ecosystem through mining of nuclear fuel, nuclear testing and occasional nuclear disasters such as Chernobyl accident or recent blast at Fukushima nuclear plant, Japan, in the aftermath of powerful earthquake (magnitude-9.0 on Richter scale on March 11, 2011), triggering a huge tsunami (Achal et al. 2012a). Kumar et al. (2011a) evaluated the uranium tolerance and the binding role of five strains of Serratia marcescens. The phylogenetic analyses of 16S rRNA gene sequences showed their correlation with $S$. marcescens ATCC13880 ( $\geq 99.4 \%$ similarity). The minimum inhibitory concentrations (MICs) for uranium $\mathrm{U}(\mathrm{VI})$ exhibited by these natural isolates ranged from $3.5-4.0 \mathrm{mM}$. All these isolates were able to remove nearly $91 \%(21 \mathrm{mg} / \mathrm{L})$ and $65 \%(300 \mathrm{mg} / \mathrm{L})$ of
$\mathrm{U}(\mathrm{VI})$ on being faced with $100 \mu \mathrm{M}(23.8 \mathrm{mg} / \mathrm{L})$ and $2 \mathrm{mM}$ $(476 \mathrm{mg} / \mathrm{L})$ uranyl nitrate solutions, respectively, at $\mathrm{pH} 3.5$ within the $10 \mathrm{~min}$ of exposure. The study suggested that the natural subgroups of $S$. marcescens owing to their superior $\mathrm{U}$ tolerating and binding properties appeared to be ideal organisms for in situ cleanup of uranium from metalcontaminated sites.

Bacillus and Pseudomonas species have been found effective for the remediation of uranium-contaminated site (Kumar et al. 2008b). A metal-resistant bacterial strain, Pseudomoas aeruginosa J007, isolated from a uranium mine of Uranium Corporation of India Ltd., Jaduguda, India, showed $U$ resistance and accumulation (maximum of $275 \mathrm{mg} \mathrm{U} / \mathrm{g}$ cell DW) following incubation in $100 \mathrm{mg} \mathrm{U} / \mathrm{L}$, at $\mathrm{pH} 4.0$, for $6 \mathrm{~h}$. Microcosm data confirmed that the strain could remove $99 \%$ soluble uranium and sequester it as $\mathrm{U}$ oxide and phosphate minerals while maintaining its viability (Choudhary and Sar 2011). Achal et al. (2012a) evaluated microbially induced calcite precipitation (MICP) for its potential to remediate strontium ( $\mathrm{Sr}$ )-contaminated aquifer quartz sand induced by Sr resistant Halomonas spp. for its potential role in bioremediation. The bacterial strain caused $80 \%$ removal of $\mathrm{Sr}$ from soluble-exchangeable fraction of the aquifer. They suggested that MICP sequesters soluble strontium as biominerals and plays an important role in bioremediation. These studies contributed significantly to gain insight into bacterial interaction with radionuclides and will be useful in understanding the role of native microorganisms inhabiting radionuclides-contaminated sites in biogeochemical cycling of uranium and in bioremediation applications.

Despite the great advantages of phyto- and bioremediation, this approach has low effectiveness in the treatment of contaminated ecosystems having high toxicity of chemical contaminants leading to the restricted use of bioremediation (Robinson et al. 2009). Therefore, bioremediation has been fundamentally approached as 'black box' as sometimes it succeeds and sometimes it fails. This led to the evolution of 'Systems biology approach to bioremediation' (Chakraborty et al. 2012).

\section{Systems biology approach to bioremediation}

At present, modern tools of genomics, transcriptomics, metabolomics, proteomics, signaling systems and synthetic biology are opening new avenues for biotechnological advances applying basic engineering principles like modularization, rational design and modeling to the construction of complex biological networks for developing its better understandings (Checa et al. 2012; Chakraborty et al. 2012). Systems biology is an integrated research approach to study complex biological systems by investigating interactions and networks at the molecular, 
cellular, community and ecosystem levels. It has tremendous implications for our fundamental understanding of hydrobiogeochemical processes (Chakraborty et al. 2012). The metabolic data, obtained from surface water from Gulf of Maine, provided 36,111 sequences, derived from environmental phytoplankton Thaumarchaea, for biogeochemical processes such as nitrification and inorganic carbon fixation (Tully et al. 2012).

Systems biology approach has been adopted to identify viable plant species, bacteria, fungi and specific genes for bioremediation and to understand the mechanisms involved in processes such as resistance, tolerance, accumulation, filtration and metabolism of toxic metals in biological systems in order to remediate or mitigate environmental pollution (Kanmani et al. 2012; Dong et al. 2013; Vrionis et al. 2005). In order to identify and track the entire microbial community during bioremediation processes, metagenomic analysis including $16 \mathrm{~S}$ rRNA-based clone libraries have been broadly utilized for heavy metals (Vrionis et al. 2005; Cardenas et al. 2008; Hemme et al. 2010). The Bacillus cereus strain XMCr-6, isolated from chromium-contaminated soils, identified on the basis of biochemical characteristics and $16 \mathrm{~S}$ rRNA gene sequence analysis, exhibited complete reduction of $100 \mathrm{mg} / \mathrm{L} \mathrm{Cr}$ (VI) within $48 \mathrm{~h}$ under aerobic conditions (Dong et al. 2013). Similarly, functionalized materials such as polycarbonate hydrogels are able to sequester metal ions (viz. $\mathrm{Pb}$ ) from aqueous solution (Kawalec et al. 2013).

Systems biology deals with integrated systems having increased accuracy and higher versatility for understanding the complex chemical and biochemical phenomena. Wick's laboratory is dealing with the potential use of a hybrid technology that combines bioremediation and electrokinetics for the treatment of contaminated ecosystem (Geneve and Fernandez 2008; Brunk et al. 2011). A large number of enzymes from bacteria, fungi, and plants are involved in the biodegradation of toxic pollutants. On one hand systems biology approach has revealed that toxic heavy metals (like As, Cd) could be transferred and accumulated in animals and human beings via food chain, which would cause DNA damage and carcinogenic effects by their mutagenic ability (Seth et al. 2007, 2008), while on the other hand its approach on bioremediation would contribute toward developing advanced bioprocess technology to reduce the toxicity of the pollutants and also to obtain novel useful biomaterials (Leung 2004; Karigar and Rao 2011).

Special consideration has been given to studies that have increased the understanding of how microbial activities are linked to the biogeochemistry of toxic heavy metals such as arsenic, by examining (1) where and in which forms arsenic occurs in the mining environment, (2) microbial activity in the context of arsenic mineral dissolution and the mechanisms of arsenic resistance, (3) the minerals used and technologies applied in the biomining of arsenic, and (4) how microbes can be used to clean up post-mining environments (Drewniak and Sklodowska 2013). Wang et al. (2013) revealed that the cooperation of surface proteins OmcA and MtrC makes the reduction of heavy metals more efficient. They suggested that direct microbial $\mathrm{Cr}(\mathrm{VI})$ reduction and $\mathrm{Fe}(\mathrm{II})$ (hematite)-mediated $\mathrm{Cr}(\mathrm{VI})$ reduction mechanisms may co-exist in the reduction processes.

Groundwater and soil at the Area 3 FRC site in Oak Ridge, USA, not only is polluted with uranium toxicity (up to $200 \mu \mathrm{M})$ but also poses a unique bioremediation problem due to its acidic $\mathrm{pH}(\sim 3)$, high nitrate $(200 \mathrm{mN})$, and high calcium concentration along with presence of chlorinated organic solvents. There also, successful application of systems biology tools demonstrated deeper understanding of the microbiology at play in the subsurface. The researchers identified Anaeromyxobactor, Acidovorax, Desulfosporosinus, Geobacter and Geothrox spp. presence concomitant with U(VI) reduction (Cardenas et al. 2008; Vrionis et al. 2005). The metagenomic analysis revealed a highly enriched community dominated by denitrifying proteobacteria (Hemme et al. 2010).

However, the aforesaid biotechnological advances in the field of bioremediation are being not implemented universally across the globe but only in the advanced or developed countries. The poor and developing countries are out of the race in adopting the systems biology approach for bioremediation. The another drawback for bioremediation is that sometimes the process becomes reversible and the remediation process may not be sustainable, if not handled carefully.

For example, heavy metals such as cadmium and lead may not be readily absorbed or captured by organisms, and the assimilation of metals such as mercury into the food chain may worsen matters (Kensa 2011). In such circumstances, phytoremediation should be preferred (Kumar and Mani 2012).

\section{Phytoremediation}

Pilon-Smits (2005) interestingly defined phytoremediation as 'the use of plants and their associated microbes for environmental cleanup', which is a cost-effective, noninvasive alternative technology for engineering-based remediation methods.

A recent study regarding the phytoremediation potential of Helianthus annuus L. in sewage-irrigated Indo-Gangetic alluvial soils in India (Mani et al. 2012b) indicates that $H$. annuus $\mathrm{L}$. is highly sensitive to $\mathrm{Cr}$ and $\mathrm{Zn}$ in terms of metal pollution, and for $\mathrm{Cr}$ phytoremediation, humic acid treatment at $500 \mathrm{~mL} / \mathrm{acre}$ increased the phytoremediation 
potential of $H$. annuus $\mathrm{L}$. and induced 3.21 and $3.16 \mathrm{mg} / \mathrm{kg}$ of $\mathrm{Cr}$ accumulation in the roots and shoots, respectively. The authors recommend the use of this plant for the phytoremediation of $\mathrm{Cr}$ in the sewage-irrigated Gangetic alluvial soils. An overview of biotechnological approaches for phytoremediation has been illustrated in Fig. 1. The illustration that has been modified from Dhankher et al. (2011) depicts that excreted compounds facilitate mobilization, enhance transportation in the root cell membrane and facilitate translocation to the shoot. Increased levels of root and xylem chelators (acids, GSH) enhance plant tolerance to the pollutant and its mobilization in the xylem. Enhanced levels of enzymes modify, conjugate or degrade pollutants and facilitate tolerance, degradation, sequestration or volatilization. Enhanced levels of phloem chelators facilitate remobilization to reproductive tissues. Kumar et al. (2008a) reported greater accumulation of heavy metals in Nelumbo nucifera in Pariyej community reserve (wetland) of Gujarat State, India. Based on the concentration and toxicity status in the lake's vegetation, the six heavy metals were arranged in the following descending order: $\mathrm{Zn}>\mathrm{Cu}>\mathrm{Pb}>\mathrm{Ni}>\mathrm{Co}>\mathrm{Cd}$. Species such as Typha angustata and Ipomoea aquatica were also proposed as bioremediants.

Wu et al. (2010) point out that the current investigation of non-crop-hyperaccumulators will be of little significance in the application and pragmatic development in the future should be cropped hyperaccumulators (newly termed as 'cropaccumulators') by transgenic or symbiotic approach. They put forward a set of universal procedures, which is novel, tentative and adaptive to evaluate hyperaccumulators' feasibility before large-scale commercialization. Further, Wu et al. (2012) reported that ethylenediamine disuccinic acid (EDDS) significantly increased soil solution dissolved organic carbon (DOC) and $\mathrm{pH}$ and increased soil plant-available metals in Sedum plumbizincicola, resulting in high soil concentrations of soluble metals and high risk of groundwater contamination. After repeated phytoremediation of metal-contaminated soils the efficiency of metal removal declines as the concentrations of bioavailable metal fractions decline, however, traditional organic materials (rice straw and clover) are much more effective and environmentally friendly amendments than EDDS in enhancing phytoremediation efficiency of $\mathrm{Cd}-$ contaminated soil. Some recent biotechnological advances in the field of phytoremediation have been illustrated under the Table 2.

Challenges and opportunities in phytoremediation

Phytoremediation technology is still in its early development stages, and full-scale applications are still limited. For widespread future use of this technique, it is important that public awareness about this technology is considered and clear and precise information is made

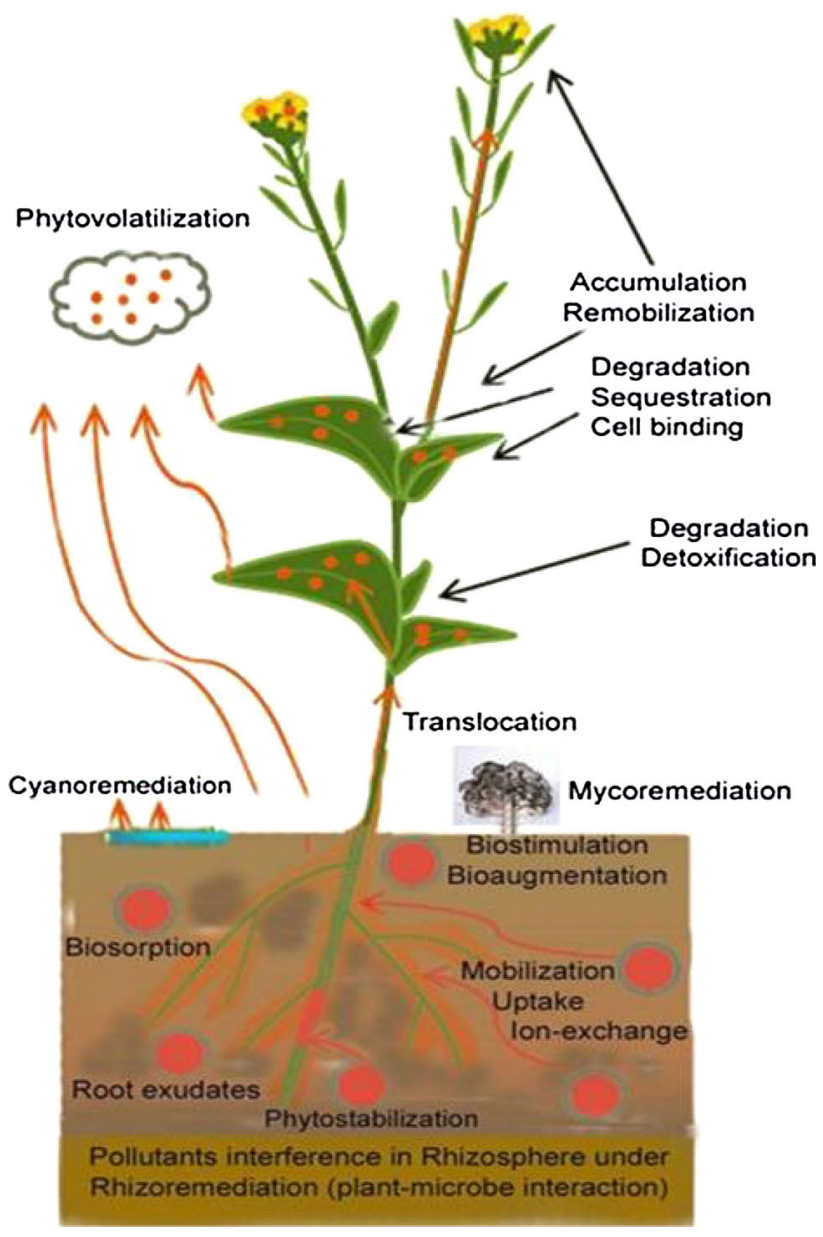

Fig. 1 An overview of biotechnological approaches for phytoremediation (modified from Dhankher et al. 2011)

available to the general public to enhance its acceptability as a global sustainable technology to be widely used. Biological processes including plant-microbe interaction and rhizospheric processes, plant uptake, translocation mechanisms, tolerance mechanisms and plant chelation significantly affect the efficiency of phytoremediation (Pilon-Smits 2005). The uptake of metals from the soil depends on different factors such as their soluble content in it, soil $\mathrm{pH}$, plant growth stages frequency of harvesting types of species, fertilizers and soil (Sharma et al. 2006; Ismail et al. 2005). The application of phytoremediation for the control of environmental pollution has several limitations that require further intensive research on plants and sitespecific soil conditions. Environmental conditions also determine the efficiency of phytoremediation as growth of plants are adversely affected by extreme environmental conditions, toxicity, and physicochemical conditions of soil in the contaminated soil-water-plant ecosystems (Danh et al. 2009).

Articles dealing with phytotechnologies emphasized the low costs of this emerging technology, and it was 
Table 2 Some plants having phytoremediation potential and heavy metals they can remediate

\begin{tabular}{|c|c|c|c|}
\hline S. No. & Species & Metals & References \\
\hline 1. & Pteris vittata & $\mathrm{Cu}, \mathrm{Ni}, \mathrm{Zn}, \mathrm{As}$ & Ma et al. (2001) \\
\hline 2. & Thlaspi, Eichhornia, Lemna, Hydrocotyle, spp. & $\mathrm{Cd}, \mathrm{Cu}, \mathrm{Ni}, \mathrm{Pb}, \mathrm{Zn}$ & Prasad and Freitas (2003) \\
\hline 3. & Brassica juncea & $\mathrm{Se}, \mathrm{Cd}$ & Banuelos et al. (2005) \\
\hline 4. & Helianthus annuus & $\mathrm{Cd}$ & Mani et al. (2007) \\
\hline 5. & Populus sp. & $\mathrm{Hg}$ & Lyyra et al. (2007) \\
\hline 6. & Husk of Oryza sativa and Zea mays & $\mathrm{Pb}$ & Abdel-Ghani et al. (2007) \\
\hline 7. & Brassica juncea and Alyssum sp. & $\mathrm{Pb}, \mathrm{Ni}$ & Chaney et al. (2007) \\
\hline 8. & $\begin{array}{l}\text { Grerillea pteridifolia, Eucalyptus camaldulensis, } \\
\text { Dalbergia sissoo, Acacia nilotica, etc. }\end{array}$ & $\mathrm{As}, \mathrm{Cd}, \mathrm{Cr}, \mathrm{Cu}, \mathrm{Hg}$ & Prasad (2007) \\
\hline 9. & Brassica napus & $\mathrm{Cd}$ & Selvam and Wong (2008) \\
\hline 10. & Typha latifolia & $\mathrm{Pb}$ & Tiwari et al. (2008) \\
\hline 11. & Nelumbo nucifera & $\mathrm{Zn}, \mathrm{Cu}, \mathrm{Pb}, \mathrm{Ni}, \mathrm{Co}, \mathrm{Cd}$ & Kumar et al. (2008a) \\
\hline 12. & Amaranthus viridis & $\mathrm{Cr}$ & Liu et al. (2008) \\
\hline 13. & Helianthus annuus & $\mathrm{Cu}, \mathrm{Zn}, \mathrm{Pb}, \mathrm{Hg}, \mathrm{As}, \mathrm{Cd}, \mathrm{Ni}$ & Jadia and Fulekar (2008) \\
\hline 14. & Trifolium pretense & Cs & Wu and Tang (2009) \\
\hline 15. & Spinacea oleracea & $\mathrm{Pb}, \mathrm{Zn}$ & Nouri et al. (2009) \\
\hline 16. & Vetiveria zizanioides & $\mathrm{Cd}, \mathrm{Pb}$ & Danh et al. (2009) \\
\hline 17. & Nicotiana tabacum & $\mathrm{Cd}$ & Wojas et al. (2009) \\
\hline 18. & Brassica juncea & $\mathrm{Pb}$ & Zarei et al. (2010) \\
\hline 19. & Alyssum lesbiacum & $\mathrm{Ni}$ & Kramer (2010) \\
\hline 20. & Lupinus luteus & $\mathrm{Cu}, \mathrm{Cd}, \mathrm{Pb}$ & Dary et al. (2010) \\
\hline 21. & Paspalum, Brassica, Ammania, Vetiveria & $\mathrm{As}, \mathrm{Pb}, \mathrm{Cu}, \mathrm{Zn}, \mathrm{Cd}$ & Mukhopadhyay and Maiti (2010) \\
\hline 22. & Populus tremula & $\mathrm{Zn}, \mathrm{Cd}, \mathrm{Cu}$ & Ruiz et al. (2011) \\
\hline 23. & Populus tremula & $\mathrm{Zn}, \mathrm{Cd}, \mathrm{Cu}$ & Pierre et al. (2011) \\
\hline 24. & Beta maritime & $\mathrm{Pb}$ & de la Fuente et al. (2011) \\
\hline 25. & Sedum plumbizincicola & $\mathrm{Cd}, \mathrm{Zn}, \mathrm{Cu}$ & Wu et al. (2012) \\
\hline 26. & Pistia stratiotes & $\mathrm{Cd}, \mathrm{Pb}, \mathrm{Zn}$ & Vesely et al. (2012) \\
\hline 27. & Spinacea oleracia & $\mathrm{Cd}, \mathrm{Pb}$ & Mani et al. (2012a, c) \\
\hline 28. & Helianthus annuus & $\mathrm{Cr}, \mathrm{Zn}$ & Mani et al. (2012b) \\
\hline 29. & Biochar of Oryza sativa & $\mathrm{Cu}, \mathrm{Pb}, \mathrm{Cd}$ & Jiang et al. (2012a) \\
\hline 30. & Gmelina arborea & $\mathrm{Al}$ & Dudhane et al. (2012) \\
\hline 31. & $\begin{array}{l}\text { Euonymus japonicus, Pittosporum tobira and } \\
\text { Cupressus Blue Ice }\end{array}$ & $\mathrm{Cd}, \mathrm{As}$ & Guo et al. (2012a) \\
\hline 32. & Arabidopsis thaliana & $\mathrm{Cd}$, As & Guo et al. (2012b) \\
\hline 33. & $\begin{array}{l}\text { Celocia cristata, Helianthus annuиs, } \\
\text { Tagetes patula }\end{array}$ & $\mathrm{Ca}, \mathrm{Cr}, \mathrm{Mn}, \mathrm{Fe}, \mathrm{Cu}, \mathrm{Zn}, \mathrm{Pb}$ & Chatterjee et al. (2012) \\
\hline 34. & $\begin{array}{l}\text { Arabidopsis thaliana (microbe merC } \\
\text { gene assisted) }\end{array}$ & $\mathrm{Cd}$ & Kiyono et al. (2012) \\
\hline
\end{tabular}

conceptually realized that phytotechnologies must include economics (Marques et al. 2009; Guo et al. 2010). Dominguez et al. (2008) and Robinson et al. (2009) have extended the phytoremediation concept to more applied and integrated tool to manage restoration works at large scale using plants for hydraulic control along with limitation of metal uptake. This new way of understanding phytotechnologies as phytomanagement is based on the use of the contaminated land for the production of economic yield. Here, remediation is redefined within a dynamic system, which maintains the risks of the contaminants at a safe level and where the factor 'soil' generates an economic gain (energy crops, pasture, biofortified products, etc.). That means that phytotechnologies no longer have the sole goal of soil remediation but also of generating economic benefits, and this necessitates redirecting current research lines to more applied aspects.

Recent researches in phytotechnology have enhanced our understanding in the fields of plant and soil sciences; 
however, more effective and commercially feasible techniques are still required to make phytotechnology more commercially attractive. Conesa et al. (2012) have suggested the exploitation of new economic opportunities such as the production bioenergy, biochar and biofortified crops, the application of economic studies and economic evaluations as well as a new implementation protocol in the field of phytotechnologies.

\section{Mechanisms of phytoremediation}

Several mechanisms are involved in phytoremediation which are being discussed as below.

\section{Phytoextraction and phytostabilization}

Phytoextraction is a phenomenon in which hyperaccumulator plants absorb metals from soil through the root system and translocate them to the harvestable shoot, and it is possible to recover metals from the harvestable parts of plants. Phytoextraction is based on the mechanism of 'hyperaccumulation,' while phytostabilization is based on the mechanism of surface complexation and latter is involved in the phenomena of metal sorption (Xu et al. 2012). Both phytoextraction and phytostabilization are one of the few technically and economically feasible alternatives for the remediation of metal-polluted soils (Kuiper et al. 2004).

According to Chaney et al. (2007), several studies have focused on developing $\mathrm{Pb}$ extraction technologies with $B$. juncea (Zarei et al. 2010), whereas in reality, even if there was enough phosphate present in contaminated soils to give good crop yields, most $\mathrm{Pb}$ remains in the soil or the roots and, without soil amendments, B. juncea has little ability to absorb $\mathrm{Pb}$ from contaminated soils.

The technique of phytostabilization can be defined as the establishment of a vegetative cover by woody species on contaminated soils to minimize the mobility of heavy metals in polluted soils. In this process, the plant roots and microbial interaction can immobilize organic and inorganic contamination binding them to soil particles in the rhizosphere. Thus, pollutants become less bioavailable, and exposure of livestock, wildlife and human beings is reduced. Dary et al. (2010) established the phytostabilization potential of Lupinus luteus inoculated with Bradyrhizobium sp. 750 and heavy metal-resistant PGPRs (plant-growth-promoting rhizobacteria) of heavy metals mainly in roots $(\mathrm{Cu}, \mathrm{Cd}$ and especially $\mathrm{Pb})$. Coinoculation of lupines with a consortium of metal-resistant PGPR (including Bradyrhizobium sp., Pseudomonas sp. and Ochrobactrum cytisi) produced an additional improvement of plant biomass with a decrease in metal accumulation both in shoots and roots.
Guo et al. (2012a) proposed, for the first time, a phytoextracting approach of stabilizing metals from contaminated soil by nursery stocks prior to their transplantation for greening. The species (such as Euonymus japonicus, Pittosporum Tobira and Cupressus Blue Ice) following the pattern of high root retention and low risk after transplantation contributes to the feasibility of this technique for soil cleansing. In sewage sludgetreated soils, heavy metals liquefaction transformed them into the relatively stable heavy metal fractions (oxidizable and residual fractions) leading to decreased bioavailability and eco-toxicity of heavy metals (Yuan et al. 2011) in the soil-water-plant ecosystem.

\section{Phytodegradation}

It is also known as phytotransformation. It is the breakdown of contaminants taken up by plants through metabolic processes within the plant or the breakdown of contaminants external to the plant through the effect of compounds (such as enzymes) produced by the plants. The main mechanism is plant uptake and metabolism causing degradation in plants. Additionally, degradation may occur outside the plant, due to the release of compounds that cause the transformation (Mukhopadhyay and Maiti 2010).

\section{Phytovolatilization}

It is the uptake and transpiration of a contaminant by a plant, with release of the contaminant or a modified form of the contaminant to the atmosphere from the plant through contaminant uptake, plant metabolism and plant transpiration. Phytodegradation is a related phytoremediation process that can occur along with phytovolatilization. Certain inorganic constituents such as mercury may be volatilized by the tobacco plants. The leaves of plants take up the highly toxic methyl mercury, alter the chemical speciation and phytovolatilize the less toxic elemental mercury into the atmosphere. The mechanism of phytovolatilization is 'volatilization by leaves' (ITRC 2009; Mukhopadhyay and Maiti 2010).

\section{Rhizoremediation}

Among soil microorganisms, arbuscular mycorrhizal (AM) fungi provide a direct link between soil and roots and are renowned for their ability to improve plant mineral nutrients, including heavy metals (Kumar et al. 2013). There have been some reports that AM fungi can improve plant tolerance or attenuate heavy metal stress or enhance plant growth under metal contaminations (Gaur and Adholeya 2004; Wang et al. 2005). Kuffner et al. (2008) also observed that rhizospheric bacteria could contribute 
immensely to the metal extraction process of the plants although mechanism of the microbe and metal interaction is not yet well understood.

Jiang et al. (2008) found a heavy metal-resistant Burkholderia species to be promoting plant growth as well as heavy metal accumulation. Rhizospheric bacteria of Typha latifolia growing on fly ash were found to enhance the mobilization of metals significantly from the fly ash through redox conversion (Tiwari et al. 2008).

As phytoremediation is generally a slow process of extraction of metals, microbes have been used to replace the costly and non-biodegradable chelating agents to enhance the process of phytoextraction of metals. Although efficacy of this technology largely depends on the selection of suitable plant species which can accumulate metals quickly and efficiently from the contaminated soils, selected microbes can assist the uptake of metals from the contaminated soils and thus augment the phytoextraction process. Hrynkiewicz et al. (2012) concluded that single inoculation with former mycorrhiza-associated Bacillus cereus strains decreased the phytoextraction efficiency of willows by causing biotic stress; however, their joint inoculation with an ectomycorrhizal fungus proved to be a very promising method for promoting the phytoextraction of $\mathrm{Cd}$ and $\mathrm{Zn}$ through combined physiological effects on the plant.

\section{Rhizodegradation}

It is the breakdown of an organic contaminant in soil through microbial activity that is enhanced by the presence of the root zone. Rhizodegradation is also known as plantassisted degradation, plant-assisted bioremediation, plantaided in situ biodegradation and enhanced rhizosphere biodegradation. It involves the use of plants and their associated microorganisms to remediate contaminated matrices through the extraction, transformation, degradation and/or stabilization of organic and inorganic pollutants. The mechanism of rhizodegradation is 'degradation by plant rhizospheric microorganisms' (Mench et al. 2009; Mukhopadhyay and Maiti 2010).

\section{Rhizofiltration}

Now, both live and dead biomass of macrophytes such as water hyacinth (Eichhornia crassipes), Duckweed (Spirodela polyrbiza, Lemna minor) and water velvet (Azolla pinnata) are being used in rhizofiltration (Rai 2009), though dead biomass is being generally preferred in the treatment of industrial effluents due to reduced cost and easy disposal, with the ability of plants to remove up to $60 \%$ of their dry weight as toxic metals, thus markedly reducing the generation and disposal cost of the hazardous residue. Hence, rhizofiltration will be a particularly costcompetitive technology in the treatment of surface or groundwater containing relatively low concentrations of toxic metals. Vesely et al. (2012) investigated that juvenile plants had 2-5 times higher bioconcentration factor than the mature plants, and juvenile and mature plants showed high metal accumulation potential to remove more than $80 \%$ of $\mathrm{Cd}, \mathrm{Pb}$ and $\mathrm{Zn}$ in the rhizofiltration process. The mechanism of rhizofiltration is 'rhizospheric accumulation.' Rhizofiltration using terrestrial plants removes contaminants more efficiently than aquatic plants. The major limitation is that a wellengineered system is required and the $\mathrm{pH}$ of the influent solution needs to be continually adjusted to obtain optimum metal uptake (ITRC 2009).

\section{Blastofiltration}

When seedlings are grown in aerated water precipitate and concentrate toxic metals from polluted effluents, it is known as blastofiltration. Lin et al. (2002) researched on six kinds of crop seedlings for removing $\mathrm{Pb}$ from water with blastofiltration method. At the selected experimental conditions, their results showed that the concentration of $100 \mathrm{mg} / \mathrm{L} \mathrm{Pb}$ can be down to below $5 \mathrm{mg} / \mathrm{L} \mathrm{Pb}$ in $72 \mathrm{~h}$. In the dry roots of a sunflower, pea and castor-oil plant, $\mathrm{Pb}$ could be accumulated up to $91.6,40.7$ and $52.8 \mathrm{mg} / \mathrm{g}$, respectively, while corn and Chinese sorghum exhibited ability for accumulation of $\mathrm{Pb}$ in the roots too. Several traditional crop seedlings with 'super-accumulation tendency' have been suggested for a better blastofiltration application prospects in the phytoremediation of $\mathrm{Pb}$ pollution in water.

\section{Genoremediation}

The genes encoding bacterial inorganic transformation have been well characterized (Singh et al. 2011; Dhankher et al. 2011; Kumar and Mani 2012), laying the molecular genetic groundwork for enhanced metal tolerance. Diverse plant species, such as tobacco, yellow poplar, cottonwood, and rice, expressing modified merA genes, have been found resistant to at least ten times greater concentrations of $\mathrm{Hg}$ (II) than those that kill non-transgenic control. Similarly yellow poplar and cottonwood, expressing both merA and merB genes, have shown the potential for $\mathrm{Hg}$ phytovolatilization in wetlands (Lyyra et al. 2007). Genetic manipulation and the use of metal tolerant plants are accelerating the process of transmitting this technology from experimental place to fields. The popularization of the mechanisms of genoremediation has been initiated and to be adopted in many other parts of the world.

The idea of a new term 'genoremediation' was mooted and evolved during a research work on 'Enhanced 
phytoremediation' (Kumar and Mani 2010, 2012; Mani et al. 2012a). The capacity of metal accumulation and tolerance could be enhanced by over-expressing natural or modified genes encoding antioxidant enzymes, or those that are involved in the biosynthesis of glutathione and other phytochelatins. Transgenic B. juncea plant showed greater biomass and accumulation potential (of Se and $\mathrm{Cd}$ ) than the wild type (Banuelos et al. 2005). These examples make a case for continuing more research into hybridization, selective breeding, gene transfer and controlled field trials of 'engineered' taxa prior to widespread use. Later, Wojas et al. (2009) demonstrated heterologous expression of AtMRP7 in Nicotiana tabacum var. Xanthi to modify cadmium accumulation, its distribution and tolerance in plants using Arabidopsis spp. MRP7 both in the tonoplast and in the plasma membrane of tobacco. The gene overexpression increased tobacco $\mathrm{Cd}$ tolerance and $\mathrm{Cd}$ accumulation in leaf vacuoles, indicating more efficient detoxification by means of vacuolar storage. Heterologous AtMRP7 expression also led to more efficient retention of $\mathrm{Cd}$ in roots, suggesting a contribution to the control of cadmium root-to-shoot translocation. Transgenic bacteria have huge catabolic possibility for remediation of wastes.

Recent genome analysis has shown that plant species belonging to the membrane intrinsic proteins (MIP) and a silicon $(\mathrm{Si})$ transporter Lsi1 (OsNIP2;1) of the nodulin 26-like intrinsic proteins (NIP) subfamilies transport As(III) in rice and a mutation in Lsi1 resulted in a nearly $60 \%$ reduction in the As(III) influx in rice roots. T-DNA insertion in Si efflux carrier Lsi2 (NIP subfamily) locus also resulted in almost $50 \%$ reduction in As accumulation in shoot (Ma et al. 2008). Research on chelators and transporters mostly focuses on their genetic basis in order to determine how they work and how genetic engineering might help in producing more commercially desirable hyperaccumulators for phytoremediation (Pilon-Smits and LeDuc 2009).

Gene-targeted bioremediation (genoremediation) includes metal transporter genes, as well as genes that facilitate chelate production. Also, in the case of elements that can be volatilized, genes that facilitate conversion to volatile forms have been over-expressed (Dhankher et al. 2011). An overview of biotechnological approaches for genoremediation has been illustrated in Fig. 2. The illustration depicts that transgenic bacteria have huge catabolic possibility for remediating wastes; gene cloning of plants containing bacterial genes enhances degradation of organic pollutants and genes facilitate metal uptake regulation, chelator production, homeostasis as well as volatilization of pollutants.

\section{Dendroremediation}

Recently, living trees were introduced in dendroremediation to de-pollute inorganic contaminated soils in order to remove, sequester or chemically decompose the pollutants. The efficiency of dendroremediation has been proven in soils polluted with crude oils, explosives, landfill leachates, metals, pesticides, PAHs and solvents (Komives and Gullner 2006); it appears of great potential for metal phytoextraction, especially fast growing woody tree species have the high metal resistance potential, for example willows (Salix sp.), oak (Quercus ilex), birch (Betula sp.) and poplars (Populus sp.) (Gonzalez et al. 2008; Nouri et al. 2009; Pierre et al. 2011); at the same time, it is important that ecological and environmental risks of dispersing heavy metals into the ecosystems by dendroremediation strategy should be minimized by selecting the right tree species, properly managing/disposing the polluted plant materials or a combination of both options allowing re-vegetation of degraded lands (Vangronsveld et al. 2009).

\section{Metals detoxification through resistance and tolerance}

The plant's capabilities to efficiently phytoremediate a metal-contaminated soil depend on their resistance to a particular pollutant. This resistance can be attributed to mechanisms of exclusion or tolerance (Klassen et al. 2000). In an endeavor to safeguard the susceptible cellular components, a cell is capable of building up resistance to metals. Bruins et al. (2000) hypothesized five mechanisms for resistance to metal toxicity. These are: (1) active or dynamic transport, (2) development of a permeability barrier, (3) enzymatic detoxification, (4) reduction in sensitivity and (5) sequestration. Microbes are capable of using one or more of these methods to eliminate nonessential metals and normalize essential metals concentrations in their cells. To mitigate metal toxicity, plants employ internal physiological mechanisms of metal detoxification (Kramer 2010). Much research has been done in this area, but much remains to be done. Generally, detoxification involves chelation of the metal cation by ligands or organic acids, or vacuolar or cell wall sequestration away from metabolic sites in the cytoplasm, usually within localized areas in the shoot (Chaney et al. 2007; Memon and Schroder 2009).

Poirier et al. (2013) evaluated a proteomic analysis of the response of the marine bacterium Pseudomonas fluorescens BA3SM1 to $\mathrm{Cd}, \mathrm{Zn}$ and $\mathrm{Cu}$, performed by gel electrophoresis followed by mass spectrometry. Cd was the most toxic metal for P. fluorescens BA3SM1, which rapidly affected cell growth. The number of proteins upregulated (16 for 0.4. $\mathrm{mM} \mathrm{Cd}$ ) remained low in comparison with results obtained for $\mathrm{Zn}$ and $\mathrm{Cu}$ ( 28 for 1.5. $\mathrm{mM} \mathrm{Zn}$ and 44 for 1.5 . $\mathrm{mM} \mathrm{Cu}$ ). They showed that the bacterium is able to acquire a metal-resistant phenotype, making the strain BA3SM1 a promising agent for bioremediation processes. 
Fig. 2 An overview of biotechnological approaches for genoremediation (modified from Singh et al. 2011)

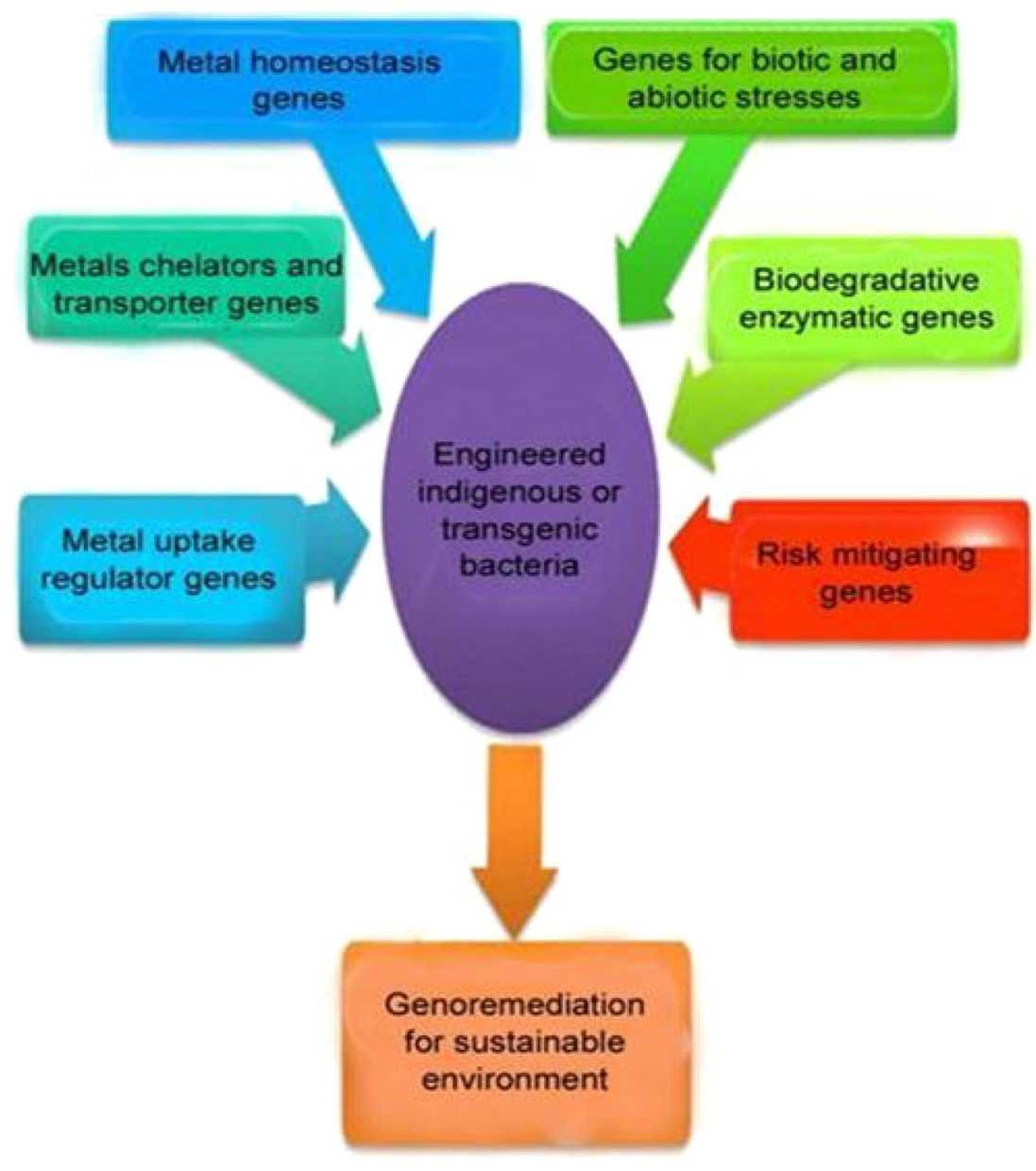

\section{Detoxification of metals through chelation}

Christopher (2000) reported other mechanisms for heavy metal detoxification in plants through the chelation of metals by organic acids (such as citrate and malate) with the subsequence compartmentalization of the ligand-metal complex. The alginate [algins are salts, extracted by treating the seaweed with a sodium carbonate solution and recovered by precipitation as alginic acid and afterward as the sodium salt, a natural polymer found in brown algae (Phaeophyceae)] products are used for chelation for removal of heavy metals from the soil-water ecosystems. The abundance of carboxylic, hydroxyl and oxo groups gives alginic acid and alginate salts strong chelating properties for metal ions. When alginic acid reacts with polyvalent ions, such as calcium, a cross-linking effect takes place, which gives the resulting alginate gel a significant structural strength. Singhal et al. (2004) found a freshwater algae (Chlorella pyrendoidosa) capable of reducing the uranium concentration in well water when the metal was immobilized in calcium alginate. Later, Kramer (2010) investigated the key role of histidine using Alyssum lesbiacum as a chelator in the tolerance as well as in the high rate $\mathrm{Ni}$ translocation.
Phytochelatins (PCs) are the main thiol peptides to chelate metals in plant cytoplasm and then the complex of these thiols with metals/metalloids are sequestered into the vacuole via ATP binding cassette transporters (ABC transporters) such as YCF1 located in Saccharomyces cerevisiae tonoplast (Brunetti et al. 2011). Dual-gene transgenic lines have been reported to cause the longest roots and the highest accumulation of $\mathrm{Cd}$ and As than single-gene transgenic lines and wild type. The dual-gene transgenic lines accumulated over twofold to tenfold cadmium/arsenite and twofold to threefold arsenate than wild type or plants expressing AsPCS1 or YCF1 alone (Guo et al. 2012b). Such stacking-modified genes involved in chelation of toxic metals and vacuolar compartmentalization represent highly promising new tools for its use in phytoremediation.

Although plant uptake is increased, chelate-assisted phytoextraction has been comprehensively discredited, because of the high leaching, plant uptake ratio of the contaminants and the persistence of chelates in the environment (Nowack et al. 2006). Extraction of Ni from the Fe oxide fraction by EDTA has been reported as a slow process (Ylivainio 2010), and the used chelating agents (EDTA, citrate and pyrophosphate) did not increase 
mobilization of heavy metals ( $\mathrm{As}, \mathrm{Cu}, \mathrm{Mn}, \mathrm{Ni}, \mathrm{Pb}$, and $\mathrm{Zn}$ ) as compared to the traditional treatment (with only $\mathrm{Fe}$ and hydrogen peroxide) which has been attributed to a very slow exchange of metals in the $\mathrm{Fe}$-ligand systems combining the chelating agents (Bennedsen et al. 2012).

Dissolved organic matter (DOM) compounds are capable of increasing the metal extraction from the soil minerals by forming dissolved metal-humic substances complexes. Wuana et al. (2010) assessed changes in heavy metal speciation and uptake by maize in a soil before and after washing with chelating organic acids such as citric acid, tartaric acid and ethylenediaminetetraacetic acid. Citric acid removed most of the metals hitherto associated with the exchangeable and reducing fractions. The findings revealed that EDTA and citric acid appeared to offer greater potentials as chelating agents to be used in remediating the highly permeable soil. Further, Yan and Lo (2012) investigated the influence of flushing duration, [S,S]-ethylenediaminedisuccinic acid (EDDS), humic acid and various combinations of EDTA, EDDS and tetrasodium pyrophosphate $\left(\mathrm{Na}_{4} \mathrm{P}_{2} \mathrm{O}_{7}\right)$ on metal extraction through column experiments. They observed higher $\mathrm{Ni}$ extraction efficiency of EDTA when the flushing time was longer. $\mathrm{Na}_{4} \mathrm{P}_{2} \mathrm{O}_{7}$ promoted the mineral dissolution which enhanced the metal extraction as a result of soil disruption and the order of metal extraction was $\mathrm{Ni}>\mathrm{Cr}>\mathrm{Cu}$, due to the different affinities between metals and $\mathrm{P}_{2} \mathrm{O}_{7}{ }^{4-}$.

Recently, the impact of chelators (citrate, EDTA) was investigated on biogenic $\mathrm{UO}_{2}$ reoxidation with ferrihydrite, goethite, and hematite minerals in anaerobic batch systems in PIPES buffer $(10 \mathrm{mM}, \mathrm{pH} 7)$ with bicarbonate for approximately 80 days. In all cases, bicarbonate increased the rate and extent of $\mathrm{UO}_{2}$ reoxidation with ferrihydrite in the presence and absence of chelators and maximum reoxidation occurred when the chelator promoted both $\mathrm{UO}_{2}$ and $\mathrm{Fe}(\mathrm{III})$ hydroxide dissolution as demonstrated with EDTA. The strong $\mathrm{Fe}(\mathrm{II})$ chelators promote reoxidation, whereas strong $\mathrm{Fe}(\mathrm{III})$ chelators impede it. These results indicate that chelators found in U-contaminated sites play a significant role in mobilizing $\mathrm{U}$, potentially affecting bioremediation efforts (Stewart et al. 2013).

\section{Detoxification of metals through root exudates}

It has been demonstrated that a common form of metal detoxification by some forest trees (such as spruce, pine, and popular) is the uptake prevention by mechanisms such as the root exudation of organic acids and/or the metal accumulation in roots by binding to the cell wall, to specific proteins such as metallothioneins and/or to biomolecules such as phytochelatins or glutathione (Brunner et al. 2008). The root-microbe interaction play major role in the performance of bioaugmentation-assisted phytoextraction applied to metal-contaminated soils as well as detoxification of heavy metals from the contaminated ecosystem (Artursson et al. 2006; Kumar and Mani 2012; Kumar et al. 2013).

\section{Hyperaccumulation of heavy metals}

Metal hyperaccumulation is a characteristic (genetically inherited traits) of model plants (approx. in $0.2 \%$ of angiosperms) for phytoremediation as these plants are tolerant to heavy metals. The knowledge of metal hyperaccumulation physiology has recently developed as a result of the advancement in molecular biology, especially for better understanding of the gene regulations and plant metal homeostasis. It is an important challenge to improve the efficiency of phytoremediation by increasing the accumulation of metals in plants or by improving key plant biological traits that should enhance metal uptake (Chaney et al. 2007; Marques et al. 2009; Guo et al. 2010).

Heavy metal pollution from both natural and anthropogenic sources results in the accumulations of metals in ecological niches. In contrast, metal hyperaccumulators can accumulate exceptionally high amounts of metals (in the thousands of ppm) and not only accumulate high levels of essential micronutrients but also absorb significant amounts of nonessential metals. In metal hyperaccumulators, the biomass production level depends on the concentration of the metals and duration of exposures. Selvam and Wong (2008) reported that Brassica napus can be a potential candidate for Cd phytoextraction. There are several species of plants such as tomato, Indian mustard, Sudan grass, sunflowers and lemon-scented Geranium, which are known for their phytoremediative abilities and are capable of uptaking large quantities of the heavy metals and continue to thrive while storing these heavy metals in its plant tissue. Those plants which can accumulate and tolerate greater metal concentrations in shoot are called hyperaccumulators.

According to Kramer (2010), over 500 hyperaccumulators have been reported to date, which include members of the Asteraceae, Brassicaceae, Caryophyllaceae, Cyperaceae, Cunouniceae, Fabaceae, Flaconrtiaceae, Laminaceae, Poaceae, Violaceae and Euphorbiaceae. The Brassicaceae is one of the very important hyperaccumulator groups. The plants used in the phytoremediation technique must have a considerable capacity of metal adsorption, its accumulation and strength to decrease the treatment time. Many families of vascular plants have been identified as metal hyperaccumulators (Prasad and Freitas 2003). There are many other processes which govern metal accumulation in plants, for example, metal mobilization and uptake from soils, 
compartmentation and sequestration within the root, efficiency of xylem to transport metal, distribution of metal in the aerial parts, sequestration and storage in leaf cells (Clemens et al. 2002; Kumari and Singh 2011).

Metabolic responses of plants to heavy metals exposure are being evaluated for the purpose of bioremediation. Liu et al. (2008) studied hydroponically grown Amaranthus viridis L. under different concentrations of $\mathrm{Cr}(\mathrm{VI})$ and found that $\mathrm{Cr}$ was accumulated primarily in the roots and exposure to $\mathrm{Cr}(\mathrm{VI})$ resulted in a decreased net photosynthetic rate, transpiration rate, stomatal conductance and intercellular $\mathrm{CO}_{2}$ concentration.

$\mathrm{Cr}(\mathrm{VI})$ exposure in floating and submerged leaves of Salvinia minima plants (Prado et al. 2010) increased sucrose contents and decreased glucose contents in $\mathrm{Cr}$ treated leaves. Mani et al. (2012c) investigated that cadmium caused significant reduction in sugar content (62\%) in radish leaf and vitamin C content $(56.4 \%)$ in coriander leaf at seedling stage, and a significant reduction in sugar content $(66.7 \%)$ and vitamin C content $(59.4 \%)$ in spinach leaf and coriander leaf, respectively, under the combined treatment $(\mathrm{Cd} 50 \mathrm{mg} / \mathrm{kg}$ and $\mathrm{Pb} 500 \mathrm{mg} / \mathrm{kg})$ at the vegetative growth stage. The dietary vegetables enhance their antioxidant activity against metal stress when applied below the critical level; however, the dosage of $\mathrm{Cd}$ higher than critical level drastically alters plant growth (stunted) and reduced yield as well as dietary contents (sugar and vitamin C) with these important vegetables, especially its antioxidant content.

Now scientists are interested in unraveling the fascinating phenomenon of metal hyperaccumulation. The understanding of metal hyperaccumulation physiology has recently improved as a result of the development of molecular biology (Sarma 2011). Plant tissue cultures such as callus, cell suspensions and hairy roots are being extensively used in phytoremediation research as model plant systems. The results derived from tissue cultures are being used to predict the responses of plants to environmental contaminants. Thus, the cost of subsequent conventional whole plant experiments has reduced (Doran 2009).

\section{Phytomanagement}

Many phytoremediation techniques are still under development, which creates the need for conducting research to find new plant species with phytoremediating potential and to generate a deeper understanding about the processes involved in tolerance, accumulation, exclusion and metabolism of toxic metals in plants.

The combination of phytoremediation and crop production is known as phytomanagement (Robinson et al. 2007). Potential plant products are non-food products such as biofuel, fiber, wood or, depending on the contamination level, animal feed. In order to show the viability of this approach, field experiments are necessary to test the implementation in agronomic practice. Longterm field trials are also necessary to test the effectiveness over time as climate and soil conditions vary from year to year and crop rotation is required. The plants that are not deeply rooted are highly affected by the heavy metals because the metals remain in the top soils and do not leach deeper (Yin et al. 2009).

There are promising examples of phytoremediation and phytomining in the fields. Chaney et al. (2007) reported that Alyssum biomass is one of the richest known $\mathrm{Ni}$ bio-ores and that these species can be effectively developed into commercial phytomining practices.

The toxicity of metals depends not only on their total concentration but also on their mobility and reactivity with other components of the ecosystem. Some factors in terms of poor agricultural practices that enhance their mobility can result in more plant uptake or reaching of these metals in groundwater (Nouri et al. 2008). These factors include the properties of metals, soil texture, $\mathrm{pH}$ and competing cations in the soil solution. There is a need to understand the evolution of new pathways for the degradation of xenobiotics and provide the basis for predicting the abilities of chemicals to undergo biological degradation and for quantifying the evolutionary rate for their elimination in the future. Biotechnological advances in terms of introducing bacterial genes or even entire bacterial endophytes for bioremediation have played an important role in moving the field of bioremediation forward toward eco-friendly protection and safety from environmental pollution.

Some case studies for phytoremediation

Some case studies for phytoremediation in India and abroad and its recent influence on waste land development, soil stabilization and soil detoxification have been briefly mentioned below:

Cattle (cow dung) accelerated the rhizospheric development and improved the plant root association in the copper mines of Globe and Tucson, Arizona, USA (ITRC 2009). The strain of Bacillus sp. KK1 caused significant increase in the urease (334\%), DHO (dehydrogenase) (14\%) and phosphatase (37\%) activity in the bioaugmented mine soil in South Korea (Govarthanan et al. 2013). In a phytoremediation process at a $\mathrm{Zn}-/ \mathrm{Cd}$-contaminated mine area, Thailand, isolated Pseudomonas aeruginosa PDMZnCd2003 (bacterium) promoted the growth of $G$. pseudochina (L) DC and enhanced the extraction of polyphenolic compounds (containing antioxidant properties) from the plant's leaves (Nakbanpote et al. 2010). 
Dowarah et al. (2009) used an integrated approach to rejuvenate a high sulfur mine overburden dumping site in the Tirap Collieries, Assam, India (near Indo-Burma hot spot biodiversity region), using a variety of plant species. The study will be helpful in long-term sustainable ecorestoration of the site. Later, several plant species were categorized as As accumulator (Paspalum, Eriochloa, Holcus, etc.), $\mathrm{Pb}$ accumulator (Brassica juncea, Vetiveria, Sesbania, etc.), $\mathrm{Cu}$ accumulator (Ammania baccifera, Scleranthus spp.) and $\mathrm{Zn}$ and $\mathrm{Cd}$ accumulator (Vetiveria, Sesbania, Viola, etc.) in a phytoremediation study of $\mathrm{Pb}$, $\mathrm{Zn}, \mathrm{Cu}$ and $\mathrm{Fe}$ tailings and mine spoils by grasses, herbs and shrubs at Dhanbad, India, and bioavailability and metal uptake by plants could be accomplished by ameliorating $\mathrm{pH}$, addition of organic amendment, fertilizer and chelating agents (Mukhopadhyay and Maiti 2010). Further, Tripathi et al. (2012) studied mine dump stability of a re-vegetated mine spoil at Dhanbad, India. They found that dump slope stability increased with a factor of safety from 1.2 to 1.4, 1.7, 1.9 and 2.1 after 2, 6, 10 and 12 years, respectively. Singh et al. (2012) also observed subsequent improvement in soil fertility and ecology of the re-vegetated mine spoil.

In a glutathione (GSH)-based phytoaccumulation study in the sewage-irrigated alluvial soils, Allahabad, India, those Brassica species (Raphanus sativus L. and Brassica napus L) accumulated significant quantity of cadmium and zinc, which had higher concentration of GSH in their shoot tissues, especially at plant maturity stage. Long-term cultivation of Helianthus annuus L. (high biomass growing plant) and Brassica species L. caused subsequent and significant improvement in physicochemical properties of the sewageirrigated soil (Mani et al. 2012a, b) which had been developed initially from dumped soil mostly with sewage sludge in 1985.

Constructed wetland with macrophytes and established landfill phytocover systems at National Aluminium Company Ltd. (NALCO)'s Angul Plant in Orissa (a hazardous mine waste storehouse contains fluoride and cyanide near the aluminum smelter and coal fly ash slurry) have resulted in minimal infiltration, isolated waste and controlled landfill gas. Now, the existing cover soil at many sites is sufficient to support an adequate root system for healthy tree growth, which is evidenced by vigorous growth of trees at abandoned landfills (MoEF 2011). Further, Mohanty et al. (2012) assessed the phytoremediation ability of Eichhornia crassipes and Brachiaria mutica to combat the problem of in situ $\mathrm{Cr}$ contamination at South Kaliapani chromite mine area in Orissa, India, and finally achieved 24-54\% and 18-33\% reduction of $\mathrm{Cr}^{\mathrm{VI}}$ from mine water, respectively, by the aforesaid plant. Loktak Lake (a Ramsar site, the wetland of international importance as per Ramsar Convention) in Manipur, having characteristic Phumdis (floating islands), is serving as receptacle for sewage and agro-chemicals. The various aquatic plants are playing a major role in phytosanitation and bioremediation process. Phytostabilization of Gumgaon manganese mine dump site by National Environmental Engineering Research Institute, Nagpur (NEERI), in India has resulted in enrichment of floral biodiversity, which is recently facilitating biodiversity products.

Chatterjee et al. (2012) studied a multi-metal (Ca, Cr, Mn, $\mathrm{Fe}, \mathrm{Cu}, \mathrm{Zn}$ and $\mathrm{Pb}$ )-contaminated soil at East Calcutta Wetlands, a Ramsar site at the eastern fringe of Kolkata city, using floriculture (growing plant species such as Celocia cristata, Helianthus annuus, and Tagetes patula). They observed significant improvement in the physicochemical properties of waste land soil and preferred the plants on the basis of their high biomass production in the order of Celocia cristata $>$ Helianthus annuus $>$ Tagetes patula for such phytoamelioration process.

Mercury-contaminated site (former thermometer manufacturing site) at Kodaikanal located around the steep slopes of the Pambar Shola Forest is being replenished by protected nature sanctuary in Tamil Nadu, India. NEERI reports Ecological Restoration of Degraded Lands through biotechnological approaches at various mining public industries located in India to improve the environmental and socioeconomic status of local population. Bioremediation of mine spoil dumps is being conducted since 1989, which enabled to restore soil productivity over 247 ha of mine soil dumps/(including coal mines) and restoration of silted soil in 2004 at different locations in India. The biocompatible technology includes site-specific specialized nitrogen fixing strains of Bradyrhizobium and Azotobacter species and nutrientmobilizing vesicular arbuscular mycorrhizal spores of Glomus and Gigaspora species in combination with industrial waste material available near the vicinity of mine site used as organic amendments to ameliorate the mine spoil and encourage re-vegetation (Prasad 2007). He reported suitable plant species for Bauxite mined area of Madhya Pradesh (Grevillea pteridifolia. Eucalyptus camaldllenis, Shorea robusta); Coal mine spoils of Madhya Pradesh (Eucalyptus hybrid, Eucalyptus camaldulensis, Acacia aurifuliformis, Dalbergia sissoo, etc.); Limestone mine spoils of outer Himalayas (Salix tetrasperma, Leucaena lellcocephala, Bauhinia retusa, etc.); Rock-phosphate mine spoils of Musoorie (Pennisetum purpureum, Saccharum spontaneum, Vitex negundo, etc.); Lignite mine spoils of Tamil Nadu (Eucalyptus species, Leucaena leucocephala, Acacia, etc.); Mica, copper, tungsten, marble, dolomite, limestone, and mine spoils of Rajasthan (Acacia tortilis, Prosopis juliflora, Acacia Senegal, Salvadora oleodes, Tamarix articulate, etc.); Iron ore wastes of Orissa (Leucaena leucocephala); and Hematite, magnetite, manganese spoil from Karnataka (Albizia lebeck). 
Phytoremediation of degraded land offers a great challenge to restore its productivity and fertility and also to re-establish the ecological cycles in the rhizosphere with identification of suitable plant species and also the amendment of some suitable blending material on such degraded land. Selective microorganism's inoculation at such sites increases the better survivability, growth and biomass of the plants. Phytoremediation of such degraded lands therefore needs an integrated approach, the use of both plants as well as site-specific microorganisms to achieve re-vegetation and restoration of fertility of the sites (Juwarkar et al. 2009). Further, Juwarkar and Singh (2010) reported a microbe-assisted phytoremediation (MAP), as one of the best environmental practice adopted for the reclamation of degraded land, from Nagpur, India. The mechanism of MAP is based on the metabolic potential of root-associated microorganisms, which are supported by the organic substrates during root excretions by a suitable microenvironment in the rhizosphere.

Momentum for the use of phytoremediation as a sustainable cleanup technique is building, particularly in application niches where other technologies are less suitable or do not exist. However, there will also likely to be integration of applications of bioremediation along with phytoremediation process. An illustration has been presented by Table 3 that differentiates the various remediation techniques with facts and figures that give the maximum benefits and efficiency of implications at applied value. The identification of intrinsic (e.g., metabolic) vs. extrinsic (e.g., symbiotic) stress-tolerance mechanisms has provided a suitable evolutionary reasoning for the apparent gaps existing between the hyperaccumulators and arbuscular mycorrhizal fungi-plant life-history strategies (Audet 2013). Ultimately, it is considered that any efforts toward cooperation, integration and assimilation of such biotechnology innovations (Kastenhofer 2007) into bioremediation strategies (e.g., 'mycorrhizal-metal-hyperaccumulators') should be first explicitly considered for their inherent environmental and (or) evolutionary contexts to avoid misleading and possibly even unproductive outcomes prior to incorporating these attributes as potential technological solutions (Audet 2013).

\section{Bioremediation with traditional wisdom}

Biological systems are being widely used as home remedies both by rural and urban inhabitants across the globe, but the intermixing of cultures has led to the introduction of several invasive exotic species into the native environment. The continuous destruction of biologically rich native ecosystems has also contributed to a gradual loss of knowledge about native diversity. The traditional communities along with ethnobiologists harbor substantial knowledge of biodiversity and their use despite the gradual economic and sociocultural transformation in their lifestyle because of globalization, and their vast knowledge should be harnessed in the emerging field of bioremediation.

One of the main characteristics of human knowledge is its dynamism. Reformulations of objectives, methodologies and theories occur in all of the sciences from time to time, and bioremediation and ethnobiology will not be different in this respect. According to Alves and Souto (2011), at a time when the world is debating so many themes concerning the benefits and dangers of scientific/biotechnological advances, the ethnosciences are discussing the possibility of linking scientific research to human priorities (especially to aid traditional populations and societies that have been historically excluded), the urgent necessities of environmental pollution and conservation, and the more cost-conscious and eco-friendly use of biological systems in bioremediation processes.

The literature indicates that bioremediation has experienced significant advances in recent yearsalthough these disciplines are still in the process of developing a sound theoretical base and unified methodological programs. From a qualitative point of view, however, improvement is still needed in terms of methodological procedures, taxonomic precision, and the use of quantitative techniques. The challenges to study bioremediation are not small, and the tendencies described in the present study may aid in defining research strategies that will maintain the quantitative growth observed in the recent years but likewise foster needed qualitative improvements.

Bioremediation currently confronts a number of challenges, and some of the most urgent items include the establishment of efficient dialogs between different academic areas that interface with biotechnology, ethnobiology, genomics and proteomics; qualitative improvements in research techniques; exchanges of experiences in relation to the results produced and the methodologies utilized; and the development of monitoring programs based on sound research into the conservation and sustainable use of natural resources.

\section{Conclusion}

This review represents recent scientific progress in usefully applying biotechnological tools for environmental management in the emerging field of bioremediation (assisted with microbes and plants) to mitigate the hazards of pollution around the world. The harmful phenomena have resulted in serious environmental and social problems around the world; these problems must be looked after for solutions elsewhere than the established physical and chemical technologies. The answer lies in 
Table 3 Comparing other remediation techniques to phytoremediation (modified from USEPA 2004; MoEF 2011)

\begin{tabular}{|c|c|c|c|c|}
\hline $\begin{array}{l}\text { S. } \\
\text { No. }\end{array}$ & $\begin{array}{l}\text { Name of } \\
\text { remediation } \\
\text { technologies }\end{array}$ & $\begin{array}{l}\text { Expected cost } \\
\text { ratio over } \\
\text { phytoremediation }\end{array}$ & Advantages over phytoremediation & Disadvantages over phytoremediation \\
\hline
\end{tabular}
1. In situ soil mixing/ 5-8 folds higher solidification/ stabilization
Well established; rapid; applicable to most metals; simple to operate during treatment; source control; not seasonally dependent

2. Water flooding/soil $8-12$ folds higher
flushing/soil
washing

3. Biostimulation/ 4-5 folds higher mycoremediation/ cyanoremediation

4. Electrokinetics

10-20 folds
higher

5. Chemical reduction/ oxidation Excavation/
disposal 6-9 folds higher

10-20 folds higher

7. Bioventing

8. Biosparging/soil vapor extraction

\begin{abstract}
Not seasonally dependent, except in cold climates; methods well established for several types of sites and contamination; implementable
\end{abstract} Established and accepted; a bioreactor can be
utilized; faster than phytoremediation

Not seasonally dependent; can be used in conjunction with phytoremediation to enhance rhizosphere biodegradation; further metal utilization is higher

Not seasonally dependent; relatively short treatment time frame; usually off site; source removal

\section{Rapid, immediate solution for site owner, nearly $100 \%$ removal; more applicable method; more technical reliable}

Source removal; Rapid; subsurface remediation of shallow aquifers and water wells are possible

Proven; implementable; vapor control; treatment under the water table; remediate deep aquifers or groundwater
Site is not restored to original form; leaching of the contaminant is a risk; result in a significant volume increase; lower sustainability for metal detoxification; require homogeneity; depth limitations; long-term residual management; risk of leaching

Removal of metals using water flushing requires $\mathrm{pH}$ change; additional treatment steps and chemical handling add complexity; possible lengthy period of treatment; hydraulic control required; homogeneity

Requires nutrient addition at a much greater level than phytoremediation; applicable to organics only; further metal utilization is less.

Useful for soil only, not for wetlands; uniformity of soil conditions is required; lower sustainability

Requires excavation; uses chemical additives; by-products generation; fertility of the soil is not sustained; hydraulic control required; accessibility and homogeneity; $\mathrm{MnO}_{2}$ crusting; application limited to coarse texture (sand to gravel)

Transfers contaminants to landfill or causes problem of waste disposal; does not treat waste; further metal utilization is less; risk of leaching

Less surface remediation; hydraulic control required; by-products generation; water treatment; required homogeneity; further metal utilization is less

Does not treat heavy-end; off-gas vapor management; less surface treatment; application limited to coarse texture (sand to gravel) multipronged and integrative applications or in systems biology approach in which biotechnological approaches, phytotechnological tools and microbial methods are combined with physical and chemical ones. The highly effective microorganisms are cultured for a variety of applications, but still the beneficial potential of microorganisms is vast and untapped in the field of bioremediation and phytoremediation. The recent approaches of bioremediation such as microbial-induced calcite precipitation (MICP) through urease hydrolyzing bacteria, formation of soluble nanoparticles as endproducts by bacteria, bacterial signaling systems for biosensors, biomineralization of radionuclides and other toxic heavy metals, synthesis of biomaterial or functionalized polymer-silica hybrid nanoparticles, genomics and proteomics of biological treatments to the contaminants, root-microbe interaction and detoxification of heavy metals have been proven as promising techniques to remediate the contaminated ecosystems.

Realizing the diversity of phytochelatins-/ phytochemicals-/phytoenzyme-based plant and tree species as well as diversity of uncultured microbes involves the application of metagenomics, and several novel plants/ microbial species are being discovered using innovative approaches. This penetrating assessment of the authors' progress in deploying multipronged eco-friendly biotechnological approaches through utilizing microbes, plants and trees, for the restoration of the polluted environment will be widely welcomed and largely accepted. Microbe-assisted phytoremediation can be best applied at sites 
having relatively shallow contamination of pollutants that are amendable to the processes such as biomineralization, biostimulation, mycoremediation, cyanoremediation, phytodegradation, phytostabilization, hyperaccumulation, dendroremediation, and rhizofiltration, for a sustainable period.

At the same time, there is urgent need to pursue, implement and popularize the recent biotechnological advances in the field of bioremediation. There exists a broader scope for innovations in science, with emphasis on cost-effectiveness, suitability and sustainability of the techniques to mitigate the impact of environmental change, contamination of food products and biological systems, impact of anthropogenic activities on the environment, and exploration of the aforesaid opportunities along with new initiatives for the restoration of environment.

Acknowledgments The compilation of this review article was supported by The Sheila Dhar Memorial Scholarship Fund, University of Allahabad, Allahabad, India; DNA Club Project of The National Academy of Sciences, India (NASI) (funded by Ministry of Science \& Technology, Department of Biotechnology, Government of India vide order No. BT/PR9045/NDB/53/21/2007); and the Indian Farmer Fertilizer Cooperative (IFFCO) Ltd., Phulpur Unit, Ghiya Nagar, Allahabad. The corresponding author is grateful to Prof. Krishna Misra, General Secretary, NASI, and Dr. Niraj Kumar, PI, DNA Club Project and Executive Secretary NASI, for guiding him regularly to attend in the scientific deliberations, in Science Communication Programs/Scientific Research Paper Writings/Workshops/Seminars/ Symposia, organized at national level and especially in the Annual Sessions of the Academy. The authors gratefully acknowledge the esteemed reviewers/editors for their critical assessment and valuable suggestions. However, opinions in the paper do not constitute an approval by the funding agencies but only reflect the personal views of the authors.

\section{References}

Abdel-Ghani NT, Hefny M, El-Chaghaby GAF (2007) Removal of lead from aqueous solution using low cost abundantly available adsorbents. Int J Environ Sci Tech 4(1):67-73

Achal V, Pan X, Zhang D (2011) Remediation of copper-contaminated soil by Kocuria flava CR1, based on microbially induced calcite precipitation. Ecol Eng 37:1601-1605

Achal V, Pan X, Fu Q, Zhang D (2012a) Biomineralization based remediation of As (III) contaminated soil by Sporosarcina ginsengisoli. J Hazar Mater 201-202:178-184

Achal V, Pan X, Zhang D (2012b) Bioremediation of strontium (Sr) contaminated aquifer quartz sand based on carbonate precipitation induced by $\mathrm{Sr}$ resistant Halomonas sp. Chemosphere 89:764 768

Acheampong MA, Meulepas RJW, Lens PNL (2010) Removal of heavy metals and cyanide from gold mine wastewater. J Chem Technol Biotechnol 85(5):590-613

Adams JA, Reddy KR (2003) Extent of benzene biodegradation in saturated soil column during air sparging. Ground Water Monitor Remediat 23(3):85-94

Ahluwalia SS, Goyal D (2007) Microbial and plant derived biomass for removal of heavy metals from wastewater. Bioresour Technol 98(12):2243-2257
Alves RRN, Souto WMS (2011) Ethnozoology in Brazil: current status and perspectives. J Ethnobiol Ethnomed 7:1-22

Artursson V, Finlay RD, Jansson JK (2006) Interactions between arbuscular mycorrhizal fungi and bacteria and their potential for stimulating plant growth. Environ Microbiol 8:1-10

Atagana HI, Haynes RJ, Wallis FM (2003) Optimization of soil physical and chemical conditions for the bioremediation of creosote-contaminated soil. Biodegradation 14:297-307

Audet P (2013) Examining the ecological paradox of the mycorrhizalmetal-hyperaccumulators. Arch Agron Soil Sci 59(4):549-558

Azouaou N, Sadaoui Z, Mokaddem H (2008) Removal of Cadmium from aqueous solution by adsorption on vegetable wastes. J Appl Sci 8(24):4638-4643

Baldwin BR, Peacock AD, Park M, Ogles DM et al (2008) Multilevel samplers as microcosms to assess microbial response to biostimulation. Ground Water 46:295-304

Banuelos G, Terry N, Leduc DL, Pilon-Smits EAH, Mackey B (2005) Field trial of transgenic Indian mustard plants shows enhanced phytoremediation of selenium-contaminated sediment. Environ Sci Technol 39:1771-1777

Batayneh AT (2012) Toxic (aluminum, beryllium, boron, chromium and zinc) in groundwater: health risk assessment. Int $\mathrm{J}$ Environ Sci Technol 9:153-162

Bennedsen LR, Anne Krischker, Jørgensen TH, Søgaard EG (2012) Mobilization of metals during treatment of contaminated soils by modified Fenton's reagent using different chelating agents. J Hazard Mater 199-200:128-134

Bruins MR, Kapil S, Oehme FW (2000) Microbial resistance to metals in the environment. Ecotoxicol Environ Saf 45(3):198-207

Brunetti P, Zanella L, Proia A, Paolis AD, Falasca G, Altamura MM, Toppi LSD, Costantino P, Cardarelli M (2011) Cadmium tolerance and phytochelatin content of Arabidopsis seedlings over-expressing the phytochelatin synthase gene AtPCS1. J Exp Bot 62(15):5509-5519

Brunk E, Ashari N, Athri P, Campomanes P, Carvalho DFF et al (2011) Pursuing the frontiers of the first-principles based computer simulations of chemical and biological systems. Chimia 65(9):667-671

Brunner I, Luster J, Gunthardt GMS, Frey B (2008) Heavy metal accumulation and phytostabilization potential of tree fine roots in a contaminated soil. Environ Pollut 152:559-568

Cardenas E, Wu WM, Leigh MB, Carley J, Carroll S, Gentry T, Luo $\mathrm{J}$, Watson D, Gu B, Ginder-Vogel M et al (2008) Microbial communities in contaminated sediments, associated with bioremediation of uranium to submicromolar levels. Appl Environ Microbiol 74:3718-3729

Chakraborty R, Wu CH, Hazen TC (2012) Systems biology approach to bioremediation. Curr Opin Biotechnol 23:1-8

Chaney RL, Angle JS, Broadhurst CL, Peters CA, Tappero RV, Sparks DL (2007) Improved understanding of hyperaccumulation yields commercial phytoextraction and phytomining echnologies. J Environ Qual 36:1429-1443

Chatterjee S, Singh L, Chattopadhyay B, Datta S, Mukhopadhyay SK (2012) A study on the waste metal remediation using floriculture at East Calcutta Wetlands, a Ramsar site in India. Environ Monit Assess 184:5139-5150

Chauhan A, Jain RK (2010) Biodegradation: gaining insight through proteomics. Biodegradation 21:861-879

Checa SK, Zurbriggen MD, Soncini FC (2012) Bacterial signaling systems as platforms for rational design of new generations of biosensors. Curr Opin Biotechnol 23:766-772

Chen SY, Lin PL (2010) Optimization of operating parameters for the metal bioleaching process of contaminated soil. Separ Purif Technol 71(2):178-185 
Chen SY, Lin LG, Lee CY (2003) Effects of ferric ion on bioleaching of heavy metals from contaminated sediment. Water Sci Technol 48(8):151-158

Chen Z, Li Z, Lin Y, Yin M, Ren J, Qu X (2013) Biomineralization inspired surface engineering of nanocarriers for $\mathrm{pH}$-responsive, targeted drug delivery. Biomaterials 34:1364-1371

Cheng SS, Hsieh TL, Pan PT, Gaop CH, Chang LH, Whang LM, Chang TC (2009) Study on biomonitoring of aged TPHcontaminated soil with bioaugmentation and biostimulation (Conference paper). 10th International in situ and on-site bioremediation symposium, Baltimore MD, May 5-8, 2009

Chikere CB, Chikere BO, Okpokwasili GC (2012) Bioreactor-based bioremediation of hydrocarbon-polluted Niger Delta marine sediment, Nigeria. Biotechnology 2:53-66

Choudhary S, Sar P (2011) Uranium biomineralization by a metal resistant Pseudomonas aeruginosa strain isolated from contaminated mine waste. J Hazar Mater 186:336-343

Christopher C (2000) Phytochelatins and their roles in heavy metal detoxification. Plant Physiol 123:828-832

Clemens S, Palmgren MG, Kramer U (2002) A long way ahead: understanding and engineering plant metal accumulation. Trends Plant Sci 7:309-315

Conesa HM, Evangelou MWH, Robinson BH, Schulin R (2012) A critical view of current state of phytotechnologies to remediate soils: still a promising tool? Sci World J. doi:10.1100/ 2012/173829

Cooley A, Rexroad R, Morrisette J, Cobb JA, Blackert D (2009) Biosparging and monitored natural attenuation of hydrocarbon, chlorinated solvent, and arsenic-impacted groundwater. 10th international in situ and on-situ bioremediation symposium. Baltimore MD, May 5-8, 2009

Danh LT, Truong P, Mammucari R, Tran T, Foster N (2009) Vetiver grass, Vetiveria zizanioides: a choice plant for phytoremediation of heavy metals and organic wastes. Int $\mathbf{J}$ Phytoremediat 11:664-691

Dary M, Chamber-Pérez MA, Palomares AJ, Pajuelo E (2010) "In situ" phytostabilisation of heavy metal polluted soils using Lupinus luteus inoculated with metal resistant plant-growth promoting rhizobacteria. J Hazard Mater 177(1-3):323-330

de la Fuente C, Clemente R, Martínez-Alcalá I, Tortosa G, Bernal MP (2011) Impact of fresh and composted solid olive husk and their water-soluble fractions on soil heavy metal fractionation; microbial biomass and plant uptake. J Hazard Mater 186(2-3):1283-1289

Deng L, Su Y, Su H, Wang X, Zhu X (2007) Sorption and desorption of lead (II) from wastewater by green algae Cladophora fascicularis. J Hazard Mater 143(1-2):220-225

Dhankher OP, Doty SL, Meagher RB, Pilon-Smits E (2011) Biotechnological approaches for phytoremediation. In: Altman A, Hasegawa PM (eds) Plant biotechnology and agriculture. Academic Press, Oxford, pp 309-328

Dominguez MT, Maranon T, Murillo JM, Schulin R, Robinson BH (2008) Trace element accumulation in woody plants of the Guadiamar Valley, SW Spain: a large-scale phytomanagement case study. Environ Pollut 152(1):50-59

Dong G, Wang Y, Gong L, Wang M, Wang H, He N, Zheng Y, Li Q (2013) Formation of soluble Cr(III) end-products and nanoparticles during $\mathrm{Cr}(\mathrm{VI})$ reduction by Bacillus cereus strain XMCr-6. Biochem Eng J 70:166-172

Doran PM (2009) Application of plant tissue cultures in phytoremediation research: incentives and limitations. Biotechnol Bioeng 103:60-76

Dowarah J, Boruah HPD, Gogoi J, Pathak N, Saikia N, Handique AK (2009) Eco-restoration of a high-sulphur coal mine overburden dumping site in northeast India: a case study. J Earth Syst Sci 118(5):597-608
Drewniak L, Sklodowska A (2013) Arsenic transforming microbes and their role in biomining processes. Environ Sci Pollut Res (in press PMID: 23299972)

Dua M, Sethunathan N, Johri AK (2002) Biotechnology bioremediation success and limitations. App Microbiol Biotechnol 59(2-3): 143-152

Dubey A, Shiwani S (2012) Adsorption of lead using a new green material obtained from Portulaca plant. Int $\mathbf{J}$ Environ Sci Technol 9:15-20

Dubey SK, Dubey J, Mehra S, Tiwari P, Bishwas AJ (2011) Potential use of cyanobacterial species in bioremediation of industrial effluents. Afr J Biotechnol 10(7):1125-1132

Dudhane M, Borde M, Jite PK (2012) Effect of aluminium toxicity on growth responses and antioxidant activities in Gmelina arborea Roxb inoculated with AM Fungi. Int $J$ Phytoremediat 14(7):643-655

Duong TTT, Verma SL, Penfold C, Marschner P (2013) Nutrient release from composts into the surrounding soil. Geoderma 195-196:42-47

Ekmekyapar F, Aslan A, Bayhan YK, Cakici A (2012) Biosorption of $\mathrm{Pb}$ (II) by Nonliving Lichen Biomass of Cladonia rangiformis Hoffm. Int J Environ Res 6(2):417-424

Ernst WHO (2006) Evolution of metal tolerance in higher plants. For Snow Landsc Res 80:251-274

Fiset JF, Blais JF, Riverso PA (2008) Review on the removal of metal ions from effluents using seaweeds, alginate derivatives and other sorbents. Rev Sci Eau 21(3):283-308

Fulekar MH, Sharma J, Tendulkar A (2012) Bioremediation of heavy metals using biostimulation in laboratory bioreactor. Environ Monit Assess 184(12):7299-7307

Gaur A, Adholeya A (2004) Prospects of arbuscular mycorrhizal fungi in phytoremediation of heavy metal contaminated soils. Curr Sci 86:528-534

Geneve JD, Fernandez M (2008) New avenues for microbial biotechnology: the beginning of a golden era. Microbiol Biotechnol 1(2):104-106

Gisbert C, Ros R, Haro AD, Walker DJ, Bernal MP, Serrano R, Navarro-Avino J (2003) A plant genetically modified that accumulates $\mathrm{Pb}$ is especially promising for phytoremediation. Biochem Biophys Res Commun 303:440-445

Gonzalez OJ, Rozas MA, Alkorta I, Garbisu C (2008) Dendroremediation of heavy metal polluted soils. Rev Environ Health 23:223234

Govarthanan M, Lee KJ, Cho M, Kim JS, Kamala-Kannan S, Oh BT (2013) Significance of autochthonous Bacillus sp. KK1 on biomineralization of lead in mine tailings. Chemosphere 8:2267-2272

Guo H, Luo S, Chen L, Xiao X, Xi Q, Wei W, Zeng G, Liu C, Wan Y, Chen J, He Y (2010) Bioremediation of heavy metals by growing hyperaccumulator endophytic bacterium Bacillus sp. L14. Bioresour Technol 101(22):8599-8605

Guo B, Liang Y, Qinglin F, Ding N, Liu C, Lin Y, Li H, Li N (2012a) Cadmium stabilization with nursery stocks through transplantation: a new approach of phytoremediation. J Hazard Mater 199200:233-239

Guo J, Xu W, Ma M (2012b) The assembly of metals chelation by thiols and vacuolar compartmentalization conferred increased tolerance to and accumulation of cadmium and arsenic in transgenic Arabidopsis thaliana. J Hazard Mater 199-200: 309-313

Gupta R, Mahapatra H (2003) Microbial biomass: an economical alternative for removal of heavy metals from wastewater. Indian J Exp Biol 41:945-966

Hassan MM (2005) Arsenic poisoning in Bangladesh: spatial mitigation planning with GIS and public participation. Health Policy 74:247-260 
Häyrynen P, Landaburu JA, Pongrácz E, Keiski RL (2012) Study of permeate flux in micellar-enhanced ultrafiltration on a semi-pilot scale: simultaneous removal of heavy metals from phosphorous rich real wastewaters. Separ Purif Technol 93(1):59-66

Hazen TC (2010) In situ: groundwater bioremediation. In: Timmis $\mathrm{KN}$ (ed) Handbook of hydrocarbon and lipid microbiology. Springer, Berlin, pp 2583-2594

Helalia AM, El-Amir S, Abou-Zeid ST, Zagholoul KF (1990) Bioremediation of saline-sodic soil by amshot grass in northern Egypt. Soil Till Res 22:109-116

Hemme CL, Deng Y, Gentry TJ, Fields MW, Wu L, Barua S, Barry K et al (2010) Metagenomic insights into evolution of a heavy metal-contaminated groundwater microbial community. ISME J 4:660-672

Hrynkiewicz K, Dabrowska G, Baum C, Niedojadlo K, Leinweber P (2012) Interactive and single effects of ectomycorrhiza formation and Bacillus cereus on metallothionein MT1 expression and phytoextraction of $\mathrm{Cd}$ and $\mathrm{Zn}$ by Willows. Water Air Soil Pollut 223:957-968

Iori V, Pietrini F, Cheremisina A, Shevyakova NI, Radyukina N, Kuzntsov VV, Zacchini M (2013) Growth responses, metal accumulation and phytoremoval capability in Amaranthus plants exposed to nickel under hydroponics. Water Air Soil Pollut 224(2):1-10

Ismail BS, Farihah K, Khairiah J (2005) Bioaccumulation of heavy metals in vegetables from selected agricultural areas. Bull Environ Contam Toxicol 74:320-327

ITRC (2009) (Interstate Technology \& Regulatory Council) Phytotechnology technical and regulatory guidance and decision trees, Revised. PHYTO-3. Washington DC

Jadia CD, Fulekar MH (2008) Vermicomposting of vegetable waste: A biophysicochemical process based on hydro-operating bioreactor. African J Biotechnol 7(20):3723-3730

Jeffries TC, Seymour JR, Newton K, Smith RJ, Seuront L, Mitchell JG (2012) Increases in the abundance of microbial genes encoding halotolerance and photosynthesis along a sediment salinity gradient. Biogeosciences 9(2):815-825

Jiang CY, Sheng XF, Qian M, Wang QY (2008) Isolation and characterization of heavy metal resistant Burkholderia species from heavy metal contaminated paddy field soil and its potential in promoting plant growth and heavy metal accumulation in metal polluted soil. Chemosphere 72:157-164

Jiang J, Xu RK, Jiang TY, Li Z (2012a) Immobilization of Cu(II), $\mathrm{Pb}(\mathrm{II})$ and $\mathrm{Cd}(\mathrm{II})$ by the addition of rice straw derived biochar to a simulated polluted Ultisol. J Hazard Mater 229:145-150

Jiang X, Wang W, Wang S, Zhang $\mathrm{B}$, Hu J (2012b) Initial identification of heavy metals contamination in Taihu Lake, a eutrophic lake in China. J Environ Sci 24(9):1539-1548

Juwarkar AA, Singh SK (2010) Microbe-assisted phytoremediation approach for ecological restoration of zinc mine spoil dump. Int $\mathrm{J}$ Environ Pollut 43(1/2/3): 236-250

Juwarkar AA, Yadav SK, Thawale PR, Kumar P, Singh SK, Chakrabarti T (2009) Developmental strategies for sustainable ecosystem on mine spoil dumps: a case of study. Environ Monit Assess 157:471-481

Kanmani P, Aravind J, Preston D (2012) Remediation of chromium contaminants using bacteria. Int $\mathrm{J}$ Environ Sci Technol 9:183-193

Karigar CS, Rao SS (2011) Role of microbial enzymes in the bioremediation of pollutants: a review. Enzyme Res. doi: $10.4061 / 2011 / 805187$

Kastenhofer K (2007) Converging epistemic cultures? Innovation 20(4):359-373

Kawalec M, Dove AP, Mespouille L, Dubois P (2013) Morpholine- functionalized polycarbonate hydrogels for heavy metal ion sequestration. Polymer Chem 4(4):1260-1270
Kensa MV (2011) Bioremediation: an overview. J Ind Pollut Control 27(2):161-168

Kim S, Park CB (2013) Bio-inspired synthesis of minerals for energy, environment and medicinal applications. Adv Funct Mater 23:10-25

Kim TW, Slowing II, Chung PW, Lin VSY (2010) Ordered mesoporous polymer-silica hybrid nanoparticles as vehicles for the intracellular controlled release of macromolecules. ACS Nano 5:360-365

Kiyono M, Oka Y, Sone Y, Tanaka M, Nakamura R, Sato MH, Pan-Hou H, Sakabe K, Inoue K (2012) Expression of bacterial heavy metal transporter MerC fused with a plant SNARE, SYP121 in Arabidopsis thaliana increases cadmium accumulation and tolerance. Planta 235:841-850

Klassen SP, Malean JE, Grossl PR, Sims RC (2000) Heavy metals in the environment. J Environ Qual 29:1826-1834

Komives T, Gullner G (2006) Dendroremediation: the use of trees in cleaning up polluted soils. Phytoremediat Rhizoremediat pp 23-31

Kramer U (2010) Metal hyperaccumulation in plants. Annu Rev Plant Biol 61:517-534

Kuffner M, Puschenreiter M, Wieshammer G, Gorfer M, Sessitsch A (2008) Rhizosphere bacteria affect growth and metal uptake of heavy metal accumulating willows. Plant Soil 304:35-44

Kuiper I, Lagendijk EL, Bloemberg GV, Lugtenberg BJJ (2004) Rhizoremediation: a beneficial plant-microbe interaction. $\mathrm{Mol}$ Plant Microb Interact 17:6-15

Kumar C, Mani D (2010) Enrichment and management of heavy metals in sewage irrigated soil. LAP LAMBERT Academic Publishing AG \& Co. KG, Saarbrücken

Kumar C, Mani D (2012) Advances in bioremediation of heavy metals: a tool for environmental restoration. LAP LAMBERT Academic Publishing AG \& Co. KG, Saarbrücken

Kumar JIN, Soni H, Kumar RN, Bhatt I (2008a) Macrophytes in Phytoremediation of heavy metal contaminated water and sediments in Pariyej community reserve, Gujarat, India. Turk J Aquat Fish Sci 8:193-200

Kumar R, Joshi SR, Acharya C (2008b) Metal tolerant Bacillus and Pseudomonas from uranium rich soils of Meghalaya. Res $\mathrm{J}$ Biotechnol (Special Issue) pp 345-350

Kumar A, Bisht BS, Joshi VD, Dhewa T (2011a) Review on bioremediation of polluted environment: a management tool. Int J Environ Sci 1(6):1079-1093

Kumar R, Acharya C, Joshi SR (2011b) Isolation and analyses of uranium tolerant Serratia marcescens strains and their utilization for aerobic uranium $\mathrm{U}(\mathrm{VI})$ bioadsorption. J Microbiol 49(4):568-574

Kumar D, Shivay YS, Dhar S, Kumar C, Prasad R (2013) Rhizospheric flora and the influence of agronomic practices on them: a review. Proc Nat Acad Sci India Sec B Biol Sci 83(1):1-14

Kumari B, Singh SN (2011) Phytoremediation of metals from fly ash through bacterial augmentation. Ecotoxicology 20:166-176

Landaburu-Aguirre J, Pongrácz E, Sarpola A, Keiski RL (2012) Simultaneous removal of heavy metals from phosphorous rich real wastewaters by micellar-enhanced ultrafiltration. Separ Purif Technol 88:130-137

Lee YC, Chang SP (2011) The biosorption of heavy metals from aqueous solution by Spirogyra and Cladophora filamentous macroalgae. Bioresource Technol 102 (9):5297-5304

Lee CS, Li XD, Shi WZ, Cheung SC, Thornton I (2006) Metal contamination in urban, suburban and country park soils of Hong Kong: a study based on GIS and multivariate statistics. Sci Total Environ 356:45-61

Lesmana SO, Febriana N, Soetaredjo FE, Sunarso J, Ismadji S (2009) Studies on potential applications of biomass for the separation of 
heavy metals from water and wastewater. Biochem Engg $\mathrm{J}$ 44(1):19-41

Leung M (2004) Bioremediation: techniques for cleaning up a mess. J Biotechnol 2:18-22

Li L, Cunningham CJ, Pas V, Philp JC, Barry DA, Anderson P (2004) Field trial of a new aeration system for enhancing biodegradation. Waste Manag 24:127-137

Li M, Cheng X, Guo H (2013) Heavy metal removal by biomineralization of urease producing bacteria isolated from soil. Int Biodeterior Biodegr 76:81-85

Lin QUR, Sen LD, Qian DUR, Yao JM (2002) Phytoremediation for heavy metal pollution in water II. The blastofiltration of $\mathrm{Pb}$ from water. J Agro Environ Sci. http://en.cnki.com.cn/Article_ en/CJFDTOTAL-NHBH200206005.htm

Liu D, Zou J, Wang M, Jiang W (2008) Hexavalent chromium uptake and its effects on mineral uptake, antioxidant defence system and photosynthesis in Amaranthus viridis L. Bioresour Technol 99(7):2628-2636

Loukidou MX, Matis KA, Zouboulis AI, Liakopoulou-Kyriakidou M (2003) Removal of As(V) from wastewaters by chemically modified fungal biomass. Water Res 37(18):4544-4552

Lyyra S, Meagher RB, Kim T, Heaton A et al (2007) Coupling two mercury resistance genes in Eastern cottonwood enhances the processing of organomercury. Plant Biotechnol J 5:254-262

Ma LQ, Komar KM, Tu C, Zhang W, Cai Y, Kennelley ED (2001) A fern that hyperaccumulates arsenic. Nature 409:579

Ma X, Nonvak PJ, Ferguson J, Sadowsky M et al (2007) The impact of $\mathrm{H}_{2}$ addition or dechlorinating microbial communities. Bioremed J 11:45-55

Ma JF, Yamaji N, Mitani N, Xu XY et al (2008) Transporters of arsenite in rice and their role in arsenic accumulation in rice grain. Proc Natl Acad Sci USA 105:9931-9935

Machackova J, Wittlingerova Z, Vlk K, Zima J (2012) Major factors affecting in situ biodegradation rates of jet-fuel during largescale biosparging project in sedimentary bedrock. J Environ Sci Heal A 47(8):1152-1165

Machado MD, Soares EV, Soares HMVM (2010) Removal of heavy metals using a brewer's yeast strain of Saccharomyces cerevisiae: chemical speciation as a tool in the prediction and improving of treatment efficiency of real electroplating effluents. J Hazard Mater 180(1-3):347-353

Malaviya P, Singh A (2011) Physiochemical technologies for remediation of chromium-containing waters and wastewaters. Crit Rev Environ Sci Technol 41(12):1111-1172

Mane PC, Bhosle AB (2012) Bioremoval of some metals by living Algae Spirogyra sp. and Spirullina sp. from aqueous solution. Int J Environ Res 6(2):571-576

Mangunwardoyo W, Sudjarwo T, Patria MP (2013) Bioremediation of effluent wastewater treatment plant Bojongsoang Bandung Indonesia using consortium aquatic plants and animals. Int J Res Rev Appl Sci 14(1):150-160

Mani D, Sharma B, Kumar C (2007) Phytoaccumulation, interaction, toxicity and remediation of cadmium from Helianthus annuus $\mathrm{L}$. Bull Envion Contam Toxicol 79(1):71-79

Mani D, Sharma B, Kumar C, Balak S (2012a) Depth-wise distribution, mobility and naturally occurring glutathione based phytoaccumulation of cadmium and zinc in sewage-irrigated soil profile. Int $\mathbf{J}$ Environ Sci Technol. doi:10.1007/s13762-012-0121-z

Mani D, Sharma B, Kumar C, Pathak N, Balak S (2012b) Phytoremediation potential of Helianthus annuus L. in sewageirrigated Indo-Gangetic alluvial soils. Int J Phytoremediation 14:235-246

Mani D, Sharma B, Kumar C, Balak S (2012c) Cadmium and lead bioaccumulation during growth stages alters sugar and vitamin $C$ content in dietary vegetables. Proc Natl Acad Sci India Sect B Biol Sci 82(4):477-488
Mann S (2001) Biomineralization: principles and concepts in bioinorganic materials chemistry. Oxford University Press, Oxford

Mapanda F, Mangwayana EN, Nyanangara J, Giller KE (2005) The effect of long-term irrigation using wastewater on the heavy metal contents of soils under vegetables in Harare, Zimbabwe. Agr Ecosyst Environ 107:151-165

Marques APGC, Rangel AOSS, Castro PML (2009) Remediation of heavy metal contaminated soils: phytoremediation as a potentially promising clean-up technology. Crit Rev Environ Sci Technol 39(8):622-654

Mclean RI, Abbe GR (2008) Characteristics of Crassostrea ariakensis (Fujita 1913) and Crassostrea virginica (Gmelin 1791) in the discharge area of a nuclear power plant in central Chesapeake Bay. J Shellfish Res 27(3):517-523

Meharg AA, Williams PN, Adomako E, Lawgali YY, Deacon D, Villada A (2009) Geographical variation in total and inorganic as content of polished (white) rice. Environ Sci Technol 43:1612-1617

Memon AR, Schroder P (2009) Implications of metal accumulation mechanisms to phytoremediation. Environ Sci Pollut Res $16: 162-175$

Mench M, Schwitzgnibel JP, Schroeder P, Bert V, Gawronski S, Gupta S (2009) Assessment of successful experiments and limitations of phytotechnologies: contaminant uptake, detoxification and sequestration, and consequences for food safety. Environ Sci Pollut Res 16:876-900

MoEF (2011) A state-of-the-art report on bioremediation, its applications to contaminated sites in India. Ministry of Environment \& Forests, Paryavaran Bhawan, New Delhi Web http://moef. nic.in/downloads/public-information/BioremediationBook.pdf. Accessed 26 March 2012

Mohanty M, Pattnaik MM, Mishra AK, Patra HK (2012) Bio-concentration of chromium- an in situ phytoremediation study at South Kaliapani chromite mining area of Orissa, India. Environ Monit Assess 184:1015-1024

Mukherjee AB, Zevenhoven R, Bhattacharya P, Sajwan KS, Kikuch R (2008) Mercury flow via coal and coal utilization by-products: a global perspective. Resour Conserv Recy 52(4):571-591

Mukhopadhyay S, Maiti SK (2010) Phytoremediation of metal mine waste. Appl Ecol Environ Res 8:207-222

Najafi M, Yousefi Y, Rafati AA (2012) Synthesis, characterization and adsorption studies of several heavy metal ions on aminofunctionalized silica nano hollow sphere and silica gel. Separ Purif Technol 85(2):193-205

Nakbanpote W, Paitlertumpai N, Sukadeetad K, Meesungeon O, Noisanguan W (2010) Advances in phytoremediation research: a case study of Gynura pseudochina (L) DC. In: Fuerstner I (ed) Advanced knowledge application in practice. Sciyo, Croatia, pp 353-378

Norstrom A, Larsdotter K, Gumaelius L, Jansen JLC, Dalhammar G (2004) A small scale hydroponics wastewater treatment system under Swedish conditions. Water Sci Technol 48(11-12):161-167

Nouri J, Mahvi AH, Jahed GR, Babaei AA (2008) Regional distribution pattern of groundwater heavy metals resulting from agricultural activities. Environ Geo 55(6):1337-1343

Nouri J, Khorasani N, Lorestani B, Karami M, Hassani AH, Yousefi N (2009) Accumulation of heavy metals in soil and uptake by plant species with phytoremediation potential. Environ Earth Sci 59(2):315-323

Nowack B, Schulin R, Robinson BH (2006) Critical assessment of chelant-enhanced metal phytoextraction. Environ Sci Technol 40(17):5225-5232

Pagnanelli F, Viggi CC, Cibati A, Uccelletti D, Toroa L, Palleschi C (2012) Biotreatment of $\mathrm{Cr}(\mathrm{VI})$ contaminated waters by sulphate reducing bacteria fed with ethanol. J Hazard Mater 199-200:186-192 
Paliwal V, Puranik S, Purohit HJ (2012) Integrated perspective of effective bioremediation. Appl Biochem Biotechnol 166:903-924

Pan XL (2009) Microbially induced carbonate precipitation as a promising way to in situ immobilize heavy metals in groundwater and sediment. Res J Chem Environ 13:3-4

Pierre V, Terry M, Madeleine SG (2011) Compartmentation of metals in foliage of Populus tremula grown on soil with mixed contamination. I. From the tree crown to leaf cell level. Environ Pollut 159:324-336

Pilon-Smits E (2005) Phytoremediation. Annu Rev Plant Biol $56: 15-39$

Pilon-Smits EAH, LeDuc DL (2009) Phytoremediation of selenium using transgenic plants. Curr Opin Biotechnol 20:207-212

Poirier I, Hammann P, Kuhn L, Bertrand M (2013) Strategies developed by the marine bacterium Pseudomonas fluorescens BA3SM1 to resist metals: a proteome analysis. Aquat Toxicol 128-129:215-232

Prado C, Rodríguez-Montelongo L, González JA, Pagano EA, Hilal M, Prado FE (2010) Uptake of chromium by Salvinia minima: effect on plant growth, leaf respiration and carbohydrate metabolism. J Hazard Mater 177(1-3):546-553

Prasad MNV (2007) Phytoremediation in India. In: Willey N (ed) Phytoremediation- methods and reviews. Humana Press, Totowa, New Jersey, pp 435-454

Prasad MNV, Freitas H (2003) Metal hyperaccumulation in plantsBiodiversity prospecting for phytoremediation technology. Electron J Biotechn 6:275-321

Purakayastha TJ, Chhonker PK (2001) Influence of vesicular arbuscular mycorrhizae fungi (Glomus etunicatum L) on mobilization of zinc in wetland rice (Oryza sativa L). Biol Fertility Soils 33:323-327

Rai PK (2009) Heavy metal phytoremediation from aquatic ecosystems with special reference to macrophytes. Crit Rev Environ Sci Technol 39(9):697-753

Rajaganapathy V, Xavier F, Sreekumar D, Mandal PK (2011) Heavy metal contamination in soil, water and fodder and their presence in livestock and products: a review. J Environ Sci Technol 4:234-249

Ramasamy RK, Congeevaram S, Thamaraiselvi K (2011) Evaluation of isolated fungal strain from e-waste recycling facility for effective sorption of toxic heavy metals $\mathrm{Pb}$ (II) ions and fungal protein molecular characterization-a Mycoremediation approach. Asian J Exp Biol 2(2):342-347

Ramos JL, Marques S, Dillewijn PV, Espinosa-Urgel M, Segura A, Duque E et al (2011) Laboratory research aimed at closing the gaps in microbial bioremediation. Trends Biotechnol 29(12): 641-647

Rasmussen LD, Sorenson SJ, Turner RR, Barkay T (2000) Application of a merlux biosensor for estimating bioavailable mercury in soil. Soil Biol Biochem 32(5):639-649

Ravenscroft P, Brammer H, Richards K (2009) Arsenic pollution: a global synthesis. Royal geographical society, 1st edn. Willey Blackwell, New York

Rayu S, Karpouzas DG, Singh BK (2012) Emerging technologies in bioremediation: constraints and opportunities. Biodegradation 23:917-926

Robinson BH, Green SR, Chancerel B, Mills TM, Clothier BE (2007) Popular for the phytomanagement of boron contaminated sites. Environ Pollut 150:225-233

Robinson BH, Banuelos G, Conesa HM, Evangelou MWH, Schulin R (2009) The phytomanagement of trace elements in soil. Crit Rev Plant Sci 28(4):240-266

Robinson C, Brömssen MV, Bhattacharya P, Häller S, Bivén A, Hossain M, Jacks G, Ahmed KM, Hasan MA, Thunvik R (2011) Dynamics of arsenic adsorption in the targeted arsenic-safe aquifers in Matlab, south-eastern Bangladesh: insight from experimental studies. Appl Geochem 26:624-635

Ruiz ON, Alvarez D, Gonzalez-Ruiz G, Torres C (2011) Characterization of mercury bioremediation by transgenic bacteria expressing metallothionein and polyphosphate kinase. BMC Biotechnol 11:82-89

Sarma H (2011) Metal hyperaccumulation in plants: a review focussing on phytoremediation technology. J Environ Sci Technol 4(2):118-138

Saunders RJ, Paul NA, Hu Y, de Nys R (2012) Sustainable sources of biomass for bioremediation of heavy metals in wastewater derived from coal-fired power generation. PLoS ONE. doi: 10.1371/journal.pone.0036470

Say R, Yimaz N, Denizli A (2003) Removal of heavy metal ions using the fungus Penicillium canescens. Adsorpt Sci Technol 21:643-650

Schiewer S, Patil SB (2008) Pectin-rich fruit wastes as biosorbents for heavy metal removal: equilibrium and Kinetics. Bioresour Technol 99(6):1896-1903

Selvam A, Wong JW (2008) Phytochelatin synthesis and cadmium uptake of Brassica napus. Environ Technol 29:765-773

Seth CS, Chaturvedi PK, Misra V (2007) Toxic effect of arsenic and cadmium alone and in combination on Giant duckweed (Spirodela polyrrhiza L) in response to its accumulation. Environ Toxicol 22:539-549

Seth CS, Chaturvedi PK, Misra V (2008) The role of phytochelatins and antioxidants in tolerance to $\mathrm{Cd}$ accumulation in Brassica juncea L. Ecotoxicol Environ Saf 71:76-85

Seviour RJ, Mino T, Onuki M (2003) The microbiology of biological phosphorus removal in activated sludge systems. FEMS Microbiol Rev 27(1):99-127

Sharma RK, Agrawal M, Marshall F (2006) Heavy metal contamination in vegetables grown in wastewater irrigated areas of Varanasi. Bull Environ Contam Toxicol 77:312-318

Shirdam R, Khanafari A, Tabatabaee A (2006) Cadmium, nickel and vanadium accumulation by three strains of marine bacteria. Iran J Biotechnol 4(3):180-187

Siezen RJ, Galardini M (2008) Genomics of biological wastewater treatment. Microbial Biotech 1(5):333-340

Singh J, Kalamdhad AS (2013) Assessment of bioavailability and leachability of heavy metals during rotary drum composting of green waste (Water hyacinth). Ecol Eng 52:59-69

Singh JS, Abhilash PC, Singh HB, Singh RP, Singh DP (2011) Genetically engineered bacteria: an emerging tool for environmental remediation and future research perspectives. Gene 480:1-9

Singh RS, Tripathi N, Chaulya SK (2012) Ecological study of revegetated coal mine spoil of an India dry tropical ecosystem along an age gradient. Biodegradation 23:837-849

Singhal RK, Joshi S, Tirumalesh K, Gurg RP (2004) Reduction of uranium concentration in well water by Chlorella (Chlorella pyrendoidosa) a fresh water algae immobilized in calcium alginate. J Radioanal Nuclear Chem 261:73-78

Sivakumar D (2012) Experimental and analytical model studies on leachate volume computation from solid-waste. Int J Environ Sci Technol. doi:10.1007/s13762-012-0083-1

Stamets P (2005) Mycelium running: how mushroom can help save the world. Ten Speed Press, Crown Publishing Group, New York

Stewart BD, Girardot C, Spycher N, Sani RK, Peyton BM (2013) Influence of chelating agents on biogenic uraninite reoxidation by $\mathrm{Fe}(\mathrm{III})$ hydroxides. Environ Sci Technol 47(1):364-371

Sud D, Mahajan G, Kaur MP (2008) Agricultural waste material as potential adsorbent for sequestering heavy metals ions from aqueous solutions: a review. Bioresour Technol 99(14): $6017-6027$ 
Tang CY, Criddle QS, Fu CS, Leckie JO (2007) Effect of flux (Transmembrane pressure) and membranes properties on fouling and rejection of reverse osmosis and nanofiltration membranes treating perfluorooctane sulfonate containing wastewater. Environ Sci Technol 41:2008-2014

Taştan BE, Ertuğrul S, Dönmez G (2010) Effective bioremoval of reactive dye and heavy metals by Aspergillus versicolor. Bioresour Technol 101(3):870-876

Thapa B, Kumar AKC, Ghimire A (2012) A review on bioremediation of petroleum hydrocarbon contaminants in soil. Kathmandu Univ J Sci Eng Tech 8(1):164-170

Tits J, Fujita T, Tsukamoto M, Wieland E (2008) Uranium (VI) uptake by synthetic calcium silicate hydrates. Mater Res Soc Symp P 1107:467-474

Tiwari S, Kumari B, Singh SN (2008) Evaluation of metal mobility/ immobility in fly ash induced by bacterial strains isolated from rhizospheric Zone of Typha latifolia growing on fly ash dumps. Bioresour Technol 99:1305-1310

Tokuyama H, Hisaeda J, Nii S, Sakohara S (2010) Removal of heavy metal ions and humic acid from aqueous solutions by coadsorption onto thermosensitive polymers. Separ Purif Technol 71(1):83-88

Tripathi RD, Dwivedi S, Shukla MK, Mishra S, Srivastava S, Singh R, Rai UN, Gupta DK (2008) Role of blue green algae biofertilizer in ameliorating the nitrogen demand and fly-ash stress to the growth and yield of rice (Oryza sativa L) plants. Chemosphere 70:1919-1929

Tripathi N, Singh RS, Chaulya SK (2012) Dump stability and soil fertility of a coal mine spoil in India dry tropical environment: a long-term study. Environ Manage 50(4):695-706

Tully BJ, Nelson WC, Heidelbert JF (2012) Metagenomic analysis of a complex marine planktonic thaumarchael community from the Gulf of Maine. Environ Microbiol 14(1):254-267

Tyagi M, Fonseca MMRD, Carvalho CCCRD (2011) Bioaugmentation and biostimulation strategies to improve the effectiveness of bioremediation processes. Biodegradation 22:231-241

USEPA (2004) Cleaning up the nation's waste sites: markets and technology trends. US Environmental Protection Agency, Washington

Vangronsveld J, Herzig R, Weyens N, Boulet J et al (2009) Phytoremediation of contaminated soils and groundwater: lessons from the field. Environ Sci Pollut Res 16:765-794

Vesely T, Tlustos P, Szakova J (2012) Organic acid enhanced soil risk element $(\mathrm{Cd}, \mathrm{Pb}$ and $\mathrm{Zn})$ leaching and secondary bioconcentration in water lettuce (Pistia stratiotes $\mathrm{L}$ ) in the rhizofiltration process. Int J Phytoremediat 14(4):335-349

Vidali M (2001) Bioremediation. An overview. Pure Appl Chem 73(7):1163-1172

Viggi CC, Pagnanelli F, Cibati A, Uccelletti D, Palleschi C, Toro L (2010) Biotreatment and bioassessment of heavy metal removal by sulphate reducing bacteria in fixed bed reactors. Water Res 44(1):151-158

Vrionis HA, Anderson RT, Ortiz-Bernad I, O'Neill KR, Resch CT, Peacock AD, Dayvault R, White DC, Long PE, Lovley DR (2005) Microbiological and geochemical heterogeneity in an in situ uranium bioremediation field site. Appl Environ Microbiol 71:6308-6318

Vullo DL, Ceretti HM, Hughes EA, Ramyrez S, Zalts A (2008) Cadmium, zinc and copper biosorption mediated by Pseudomonas veronii $2 \mathrm{E}$. Bioresour Technol 99:5574-5581

Wang GQ, Huang YZ, Xiao BY, Qian XC, Yao H, Hu Y, Gu YL, Zhang C, Liu KT (1997) Toxicity from water containing arsenic and fluoride in Xinjiang. Fluoride 30:81-84
Wang F, Lin X, Yin R (2005) Heavy metal uptake by arbuscular mycorrhizas of Elsholtzia splendens and the potential for phytoremediation of contaminated soil. Plant Soil 269:225-232

Wang S, Zhang D, Pan X (2012) Effects of arsenic on growth and photosystem II (PSII) activity of Microcystis aeruginosa. Ecotoxicol Environ Saf 84:104-111

Wang Y, Sevinc PC, Belchik SM, Fredrickson J, Shi L, Lu HP (2013) Singly-cell imaging and spectroscopic analyses of $\mathrm{Cr}(\mathrm{VI})$ reduction on the surface of bacterial cells. Langmuir 29(3):950-956

Wen YM, Lin HY, Wang QP, Chen ZL (2010) Bioleaching of heavy metals from sewage sludge using acidithiobacilus thiooxidans. 2nd international symposium on aqua science, water resource and low carbon energy, Sanya, December 7-10, 2009, AIP Conference Proceedings 1251:189-192

Wojas S, Hennig J, Plaza S, Geisler M, Siemianowski O et al (2009) Ectopic expression of Arabidopsis ABC transporter MRP7 modifies cadmium root-to-shoot transport and accumulation. Environ Pollut 157(10):2781-2789

Wu HB, Tang SR (2009) Using $\mathrm{CO}_{2}$ to increase the biomass of a Sorghum vulgare $\times$ Sorghum vugare var. Sudanese hybrid and Trifolium pretense $\mathrm{L}$. and to trigger hyperaccumulation of cesium. J Hazard Mater 170:861-870

Wu G, Kang H, Zhang X, Shao H, Chu L, Ruan C (2010) A critical review on the bio-removal of hazardous heavy metals from contaminated soils: issues, progress, eco-environmental concerns and opportunities. J Hazard Mater 174(1-3):1-8

Wu L, Li Z, Akahane I, Liu L et al (2012) Effects of organic amendments on $\mathrm{Cd}, \mathrm{Zn}$ and $\mathrm{Cu}$ bioavailability in soil with repeated phytoremediation by Sedum plumbizincicola. Int J Phytoremediat 14(10):1024-1038

Wuana RA, Okieimen FE, Imborvungu JA (2010) Removal of heavy metals from a contaminated soil using organic chelating acids. Int J Environ Sci Tech 7(3):485-496

Xu H, Chen Y, Huang H, Liu Y, Yang Z (2012) Removal of lead(II) and cadmium (II) from aqueous solutions using spent Agaricus bisporus. Can J Chem Eng (in press)

Yan DYS, Lo IMC (2012) Pyrophosphate coupling with chelantenhanced soil flushing of field contaminated soils for heavy metal extraction. J Hazard Mater 199-200:51-57

Yin X, Yao C, Song J, Li Z, Zhang C et al (2009) Mercury contamination in vicinity of secondary copper smelters in Fuyang, Zhejiang Province, China; levels and contamination in top soils. Environ Pollut 157(6):1787-1793

Yin XX, Wang LH, Bai R, Huang H, Sun GX (2012) Accumulation and transformation of arsenic in the blue-green alga Synechocysis sp. PCC6803. Water Air Soil Pollut 223(3):1183-1190

Ylivainio K (2010) Effects of iron (III) chelates on the solubility of heavy metals in calcareous soils. Environ Pollut 158:3194-3200

Yuan X, Huang H, Zeng G, Li H, Wang J, Zhou C, Zhu H, Pei X, Liu Z, Liu Z (2011) Total concentrations and chemical speciation of heavy metals in liquefaction residues of sewage sludge. Bioresour Technol 102(5):4104-4110

Zarei M, Hempel S, Wubet T, Schafer T, Savaghebi G et al (2010) Molecular diversity of arbuscular mycorrhizal fungi in relation to soil chemical properties and heavy metal contamination. Environ Pollut 158:2757-2765

Zeftawy MAME, Mulligan CN (2011) Use of rhamnolipid to remove heavy metals from wastewater by micellar-enhanced ultrafiltration (MEUF). Separ Purif Technol 77(1):120-127 